\title{
Is it worth it to win the Talent War? Evaluating the Utility of Performance-Based Pay
}

\author{
Michael C. Sturman, Cornell University \\ Charlie O. Trevor, University of Wisconsin-Madison \\ John W. Boudreau, Cornell University \\ Barry Gerhart, University of Wisconsin-Madison
}

\begin{abstract}
Although the business press suggests that "winning the talent war," the attraction and retention of key talent, is increasingly pivotal to organization success, executives often report that their organizations do not fare well on this dimension. We demonstrate how, through integrating turnover and compensation research, the Boudreau and Berger (1985) staffing utility framework can be used by I-O psychologists and other HR professionals to address this issue. Employing a step-by-step process that combines organization-specific information about pay and performance with research on the pay-turnover linkage, we estimate the effects of incentive pay on employee separation patterns at various performance levels. We then use the utility framework to evaluate the financial consequences of incentive pay as an employee retention vehicle. The demonstration illustrates the limitations of standard accounting and behavioral cost-based approaches and the importance of considering both the costs and benefits associated with pay-for-performance plans. Our results suggest that traditional accounting or behavioral cost-based approaches, used alone, would have supported rejecting a potentially lucrative pay-for-performance investment. In addition, our approach should enable $H R$ professionals to use research findings and their own data to estimate the retention patterns and subsequent financial consequences of their existing, and potential, company-specific performance-based pay policies.
\end{abstract}

The ability to achieve competitive advantage through people depends in large part on the composition of the work force. This, in turn, is a function of who is hired, how they are developed, and who is retained- the latter of which is the focus of this study. Voluntary employee turnover can be either dysfunctional or functional for the organization, depending on who leaves (Boudreau, 1991; Boudreau \& 
Berger, 1985; Hollenbeck \& Williams, 1986; Trevor, 2001). Both low and high performers are generally more likely to leave an organization than are average performers (Jackofsky, 1984; Trevor, Gerhart, \& Boudreau, 1997; Williams \& Livingstone, 1994). Thus, organizations often will shed poor employees (functional turnover), but will also fail to retain star employees (dysfunctional turnover). It appears, however, that organizational practices can influence the performance distribution of leavers. Specifically, though high performers typically may leave the organization more often than do average performers, they do not necessarily do so. Although research consistently reports that an organization's pay system affects the probability of voluntary turnover (Dreher, 1982; Gerhart \& Milkovich, 1992; Griffeth, Hom, \& Gaertner, 2000; Harrison, Virick, \& William, 1996; Porter \& Lawler, 1968; Schwab, 1991; Steers \& Mowday, 1981; Trevor et al., 1997), the probability of high-performer turnover is particularly sensitive to the strength of the pay-for-performance link (Trevor et al., 1997). Consequently, organizations may be able to design compensation systems to enhance organizational value by targeting retention efforts at the dysfunctional high performer turnover.

This may, in fact, be increasingly happening as organizations in the United States and abroad are progressing toward linking pay more strongly to performance (Milkovich \& Newman, 2002). Although many organizations have expanded their use of plans that reward team, business unit, and corporate performance (Milkovich \& Newman, 2002), the predominant basis for pay-for-performance continues to be individual performance (Hewitt Associates, 2002; IOMA, 2002), and survey data indicate that companies believe individual pay-for-performance programs are effective (IOMA, 2002). Although there are concerns about the wisdom of pay-for-performance (e.g., Kohn, 1993; Pfeffer, 1998), particularly for individual performance, research reviews find ample evidence that pay-for-performance is associated with higher performance at both the individual (Jenkins, Mitra, Gupta, \& Shaw, 1998) and organizational levels of analysis (Gerhart, 2000). Such research, however, has not explicitly examined the mechanisms through which pay-for-performance plans affect individual behaviors to influence the organizational bottom line. One such mechanism involves pay-for-performance's effects on performance-specific turnover, and the associated costs and benefits that contribute to organizational financial performance.

The professional HR literature suggests that influencing the retention of high performers in particular is a crucial matter. Many articles cite the increasing difficulty in obtaining and keeping top talent (e.g., Bartlett \& Ghoshal, 2002; Branch, 1998; Chambers, Handfield-Jones, Hanking, \& Michaels, 1998; Rich, 1999). A report based on interviews of over 5,000 executives and managers (McKinsey \& Company, 1998), for example, found that $65 \%$ of executives believed that they had insufficient talent in the ranks of their top 300 leaders while only $10 \%$ strongly believed that their companies retained most 
of their high performers. Even with the recent economic slowdown, organizations face increased pressures to attract and retain top talent in their most pivotal talent areas. The Bureau of Labor Statistics projects that, by 2010, the labor supply will grow by 17 million (Fullerton \& Toosi, 2001) and labor demand will increase by 22.2 million (Berman, 2001), indicating that labor shortages will play increasing roles in the future. Moreover, even if a company is reducing employee headcount, voluntary attrition is often the first and most attractive option (Sherwyn \& Sturman, 2002). Each of these circumstances highlights the potential benefits of managerial investments that particularly facilitate topperformer retention.

Few would debate the merits of a performance-based pay practice that, all else equal, resulted in greater retention of high performers. Unfortunately, all else is far from equal when changing an organization's pay systems. Because such changes will affect total labor costs, individual employee pay levels, and subsequent employee behaviors, the critical question becomes one of whether the benefits of such a practice outweigh the costs. We propose that although the potential retention benefits of incentive pay have been recognized, they have yet to be quantified in dollar terms. Moreover, researchers have failed to adequately address actual costs of performance-based bay. Our goal here is to provide the first empirical cost-benefit assessment of the viability of performance-based pay. Our approach should contribute to the pay-for-performance literature by specifying the circumstances that affect the success of pay-for-performance plans.

Our results should also contribute to practice, as the likelihood that HR professionals would apply the research findings to their own organizations should increase if these professionals are provided with a viable technique for doing so. In this paper, we demonstrate such a technique. The employee movement utility model of Boudreau and Berger (1985) provides the means to evaluate the dollar value implications of various pay-for-performance strategies, which we illustrate with a step-bystep application to a published turnover and pay-for-performance article. In doing so, we (a) demonstrate how organizational representatives can use research findings, publicly available compensation, and turnover data, or their own data to diagnose, inform, and evaluate their own company-specific incentive pay decisions; and (b), demonstrate that this technique will often provide different conclusions from typical decision models that use only traditional cost or accounting analysis.

Utility Analysis Applied to Pay Decisions

Utility analysis is a tool for cost-benefit analysis that helps quantify the impact of human resource interventions (Cascio, 2000). Although utility analysis has been applied to numerous human 
resource program areas, most applications have concentrated in the areas of employee selection and training (Boudreau, 1991; Boudreau \& Ramstad, 2003b; 1999). The Boudreau and Berger (1985) framework represents one of the few applications to employee retention. Klass and McClendon (1996) used that framework to examine the pay policy decision of whether to lead, lag, or match the market. They gathered parameter information from published studies and simulated effects on employee separation and offer acceptance patterns. Results for bank tellers suggested that a lag policy produced higher payoffs, although "leading the market" (paying higher than the average) did enhance retention and attraction of top candidates. The authors noted that these results did not necessarily suggest using a particular pay policy, and showed how simulated reductions in citizenship behavior due to low pay might change the results. This was an important initial application of employee movement utility principles to decisions about pay.

In this paper, we focus on a different type of pay decision-how to allocate pay increases across employees at different performance levels. Trevor et al. (1997) found that pay policies providing greater pay growth for high performers (and less for low performers) substantially increased retention among high performers, encouraged separation among low performers, and, thus, increased the value of the work force. This is an appealing prospect, but it is unclear whether the enhanced workforce value would offset the cost associated with such a reward system. Such costs are quite apparent using traditional accounting or behavioral costing models, but such models have limited ability to reflect effects on workforce value; furthermore, little data exists on the actual implications of these limitations (Boudreau \& Ramstad, 2003a; 2003b). It is also unclear to what extent the enhanced workforce value would depend on such factors as the pay policy specifics, the retention pattern, and the variability in performance. The Boudreau-Berger utility framework provides a method to address these questions.

Using the Boudreau and Berger (1985) separation/acquisition utility model, our paper presents a model that captures the value associated with employee separations (turnover) and acquisitions (hires) over time. The model estimates three components in each time period: (a) movement costs-the costs associated with employee separations and acquisitions; (b) service costs-the pay, benefits, and associated expenses required to support the work force; and (c) service value-the value of the goods and services produced by the work force. The dollar-valued implications of a given pay plan, and of the subsequent separation and acquisition patterns over time, are estimated by subtracting the movement costs and service costs from the service value (i.e., subtracting the pay plan's costs from its benefits). Figure 1 shows the steps necessary to compute this estimate and the tables we employ here to illustrate these steps. 


\section{The Illustrative Case Study}

We illustrate our approach using a scenario in which a hypothetical company is considering implementing a pay-for-performance plan at the end of the year 2003. We assume that the company does not currently relate pay to performance, so, under the current strategy, all employees would receive the same pay increases over time. We compare the effects of this strategy with those of two alternative strategies that place different emphases on pay-for-performance. We choose to evaluate the implications of the three possible approaches over a 4-year period (2004 to 2007). Thus, because payfor-performance affects turnover differently at different levels of performance (Trevor et al., 1997), the 2007 workforce would reflect a different performance distribution under each of the three pay strategies. By calculating the movement costs, service costs, and service values from 2004 to 2007, we can estimate the cumulative effects of the pay strategies over the 4-year period. 1

We used a number of spreadsheets to make the necessary calculations, with each spreadsheet corresponding to a table in this paper. The spreadsheets are available from the lead author upon request, although the descriptions we provide here should be sufficient for many readers to create their own. We also make a number of assumptions to perform the necessary calculations. These assumptions are all based on published research (e.g., Trevor et al., 1997) or publicly available data (e.g., BLS, 2002). First, we draw directly from the Trevor et al. (1997) study to estimate (a) the relationship between pay growth, performance, and turnover that is captured in their survival analysis (see Appendix) and is used to calculate the turnover probabilities at each performance level under each pay strategy; (b) the baseline turnover probability necessary to compute those turnover probabilities that are specific to each performance level-pay strategy combination; and (c) the performance distribution at the beginning of our utility analysis timeframe.

It should be noted that the Trevor et al. (1997) data are from all 5,143 exempt employees hired by a large petrochemical organization between 1983 and 1988. Furthermore, Trevor et al. (1997) examined the effects of various strengths of pay-for-performance relationships based on archival data on individuals' performance and pay levels; they did not specifically manipulate the pay-for-

\footnotetext{
${ }^{1}$ The Boudreau and Berger (1985) model in its purest form would calculate the work force value in each intervening year and apply a discount factor to equalize the time value of the dollar amounts. Although these economic corrections can yield substantial changes to the estimated value (Sturman, 2000), such embellishments do not have a significant effect in this case because the changes in dollar amounts are assumed to be linear, the time frame is relatively short, and our focus is on the relative (vs. absolute) value of the different strategies. We also did not have information about the organizational tax rate, so we report our results in pretax dollars. Aftertax effects could be easily calculated by multiplying the final results by an appropriate aftertax proportion, but the relative effects of the options would not be altered.
} 
performance link as part of either an experimental or quasi-experimental design. Nonetheless, these data represent a wide variety of exempt jobs over several years, and the results provide valuable insight into the relationships between turnover, pay, and performance. Thus, the results of the Trevor et al.

(1997) study are useful for our purpose of illustrating our technique.

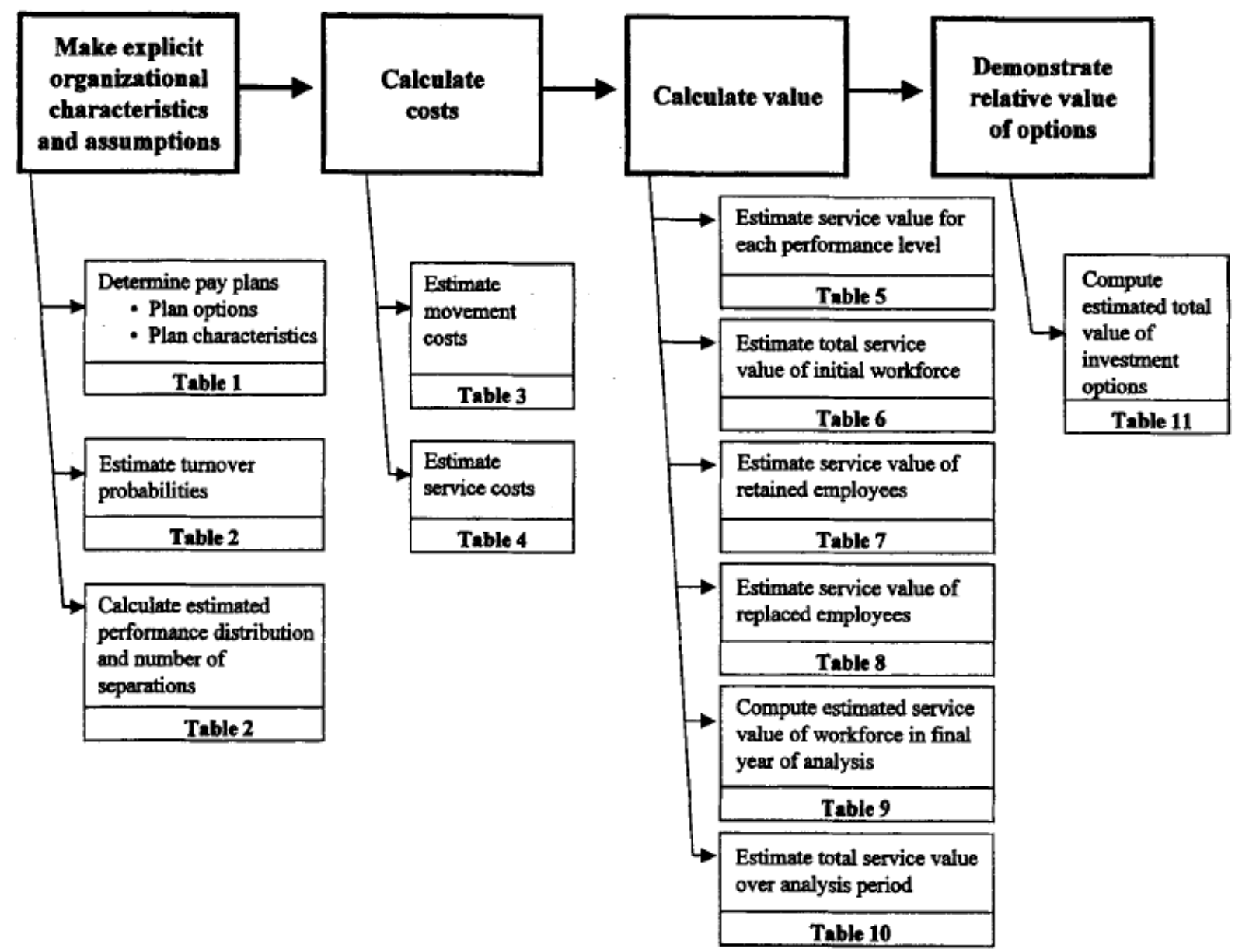

Figure 1: Flow Chart of Utility Analysis Procedure

Second, we use published surveys (BLS, 2002; WorldatWork, 2002) to help generate realistic pay strategies, determine starting average pay levels, and estimate benefit costs. Finally, we employ the results of published research studies to help provide realistic estimates of the cost of turnover (e.g., Johnson, 1995; Solomon, 1988) and the value of different levels of employee performance (Becker \& Huselid, 1992; Boudreau, 1991; Cascio, 2000; Schmidt \& Hunter, 1983). We describe the rationale for our assumptions and suggest how professionals might apply each rationale or gather their own data to customize the application for their organizations. Thus, our demonstration is intended (a) to provide information on the value of pay-for-performance plans and the extent that they should ultimately lead 
to improved organizational financial success; and (b) to enable others to use the method with their own company's data, new research findings, and/or their own estimates to create company-specific evaluations to facilitate their own decision making regarding the implementation of pay-forperformance policies.

TABLE 1

Pay Strategies and Estimated 4-Year Pay Levels for Each Strategy

\begin{tabular}{|c|c|c|c|c|c|c|c|c|c|}
\hline Performance ratings: & 1.0 & 1.5 & 2.0 & 2.5 & 3.0 & 3.5 & 4.0 & 4.5 & 5.0 \\
\hline $\begin{array}{l}\text { Pay increase for Pay Strategy } 1 \\
\text { Pay increase for Pay Strategy } 2 \\
\text { Pay increase for Pay Strategy } 3\end{array}$ & $\begin{array}{l}4 \% \\
4 \% \\
0 \%\end{array}$ & $\begin{array}{l}4 \% \\
4 \% \\
1 \%\end{array}$ & $\begin{array}{l}4 \% \\
4 \% \\
2 \%\end{array}$ & $\begin{array}{l}4 \% \\
4 \% \\
3 \%\end{array}$ & $\begin{array}{l}4 \% \\
4 \% \\
4 \%\end{array}$ & $\begin{array}{l}4 \% \\
5 \% \\
5 \%\end{array}$ & $\begin{array}{l}4 \% \\
6 \% \\
6 \%\end{array}$ & $\begin{array}{l}4 \% \\
7 \% \\
7 \%\end{array}$ & $\begin{array}{l}4 \% \\
8 \% \\
8 \%\end{array}$ \\
\hline 2003 Average pay & $\$ 47,983$ & $\$ 47,983$ & $\$ 47,983$ & $\$ 47,983$ & $\$ 47,983$ & $\$ 47,983$ & $\$ 47,983$ & $\$ 47,983$ & $\$ 47,983$ \\
\hline \multicolumn{10}{|c|}{ Pay Strategy 1: No pay/performance link } \\
\hline $\begin{array}{l}2007 \text { Average pay } \\
\text { Pay Strategy 2: Pay for perform }\end{array}$ & $\begin{array}{l}\$ 56,133 \\
\text { ce link for }\end{array}$ & $\begin{array}{l}\$ 56,133 \\
\text { ove averag }\end{array}$ & $\begin{array}{l}\text { \$56,133 } \\
\text { performers }\end{array}$ & $\$ 56,133$ & $\$ 56,133$ & $\$ 56,133$ & $\$ 56,133$ & $\$ 56,133$ & $\$ 56,133$ \\
\hline $\begin{array}{l}2007 \text { Average pay } \\
\text { Pay Strategy 3: Pay for perform }\end{array}$ & $\begin{array}{l}\$ 56,133 \\
\text { ce link for }\end{array}$ & $\begin{array}{l}\$ 56,133 \\
\text { performer }\end{array}$ & $\$ 56,133$ & $\$ 56,133$ & $\$ 56,133$ & $\$ 58,324$ & $\$ 60,577$ & $\$ 62,896$ & $\$ 65,280$ \\
\hline 2007 Average pay & $\$ 47,983$ & $\$ 49,931$ & $\$ 51,938$ & $\$ 54,005$ & $\$ 56,133$ & $\$ 58,324$ & $\$ 60,577$ & $\$ 62,896$ & $\$ 65,280$ \\
\hline
\end{tabular}

\section{Pay-for-Performance Plans and Performance-Specific Turnover}

\section{Step 1: Specify the Pay-for-Performance Options}

As is evident in Figure 1, the first major phase in estimating the costs and benefits of performance-based pay is to make explicit the relevant organizational characteristics and assumptions. The initial step within this phase is to specify the pay policy scenarios to be considered. The two key parameters needed are: (a) the current pay level in each performance category for the employees to be considered; and (b) the relationship between pay growth and performance levels (usually expressed in terms of the percentage increase awarded for each performance level). For this second parameter, we constructed three hypothetical, but realistic, performance-based pay strategies. Because we intend to provide a broad range of potential outcomes, within which most particular organizational results should fall, the strategies were chosen to range from conservative to aggressive in terms of the pay-forperformance link. In terms of performance categories, we adopted the nine performance-rating categories used by Trevor et al. (1997), which range from $1.0=$ lowest performance to $5.0=$ highest performance in 0.5 increments, because this will facilitate using other aspects of the Trevor et al. situation as an illustration. Trevor et al. (1997) created the nine categories by computing average performance over time from a rating system in which "The performance scale ranged from $1=$ lowest to 
$5=$ highest, with the five categories representing levels of consistency in meeting and exceeding the basic requirements of the job7, (p. 49). Professionals adopting our utility analysis framework should change the performance categories to reflect their own performance assessment approach.

The details of our three illustrative pay-for-performance plans are shown in Table 1. Pay Strategy 1 gives all employees the same average pay increase, regardless of performance level. Data suggest that current pay increases average 4\% (BLS, 2002; Peck, 2002; WorldatWork, 2002), so we used this value for all performance categories in Pay Strategy 1. Pay Strategy 2 creates a pay-performance link (i.e., larger pay increases as performance improves) for performers above the middle "3.0" rating, and average pay increases (i.e., 4\%) to those rated 3.0 and below. Pay Strategy 3 maintains the positive reinforcement of Pay Strategy 2, and extends the pay-for-performance link to those below the middle rating (i.e., smaller pay increases as performance worsens). Thus, Pay Strategy 1 provides no performance link, Pay Strategy 2 is more aggressive, and Pay Strategy 3 is the most aggressive.

As noted above, in addition to the pay raise strategy, Step 1 requires the setting of an initial pay level upon which the pay strategies will be applied. Because our example involves evaluating the payfor-performance strategies for white-collar employees, we used the Bureau of Labor Statistics (BLS, 2002) estimate of average 2001 white-collar (nonsales) pay, adjusted for the average salary increases of exempt workers for 2002 and 2003 (WorldatWork, 2002). This ultimately yielded a pay level of $\$ 47,983$ for the year 2003 . $^{2}$ For illustration, we simply assigned this same initial pay level to every performance category. Then, applying the percentage increase associated with each pay strategy and extrapolating for 4 future years, we projected the resulting performance-specific pay levels for the year 2007, as reported in Table 1.

In actual organizations, of course, the current pay levels would be available from company records. The same forward-projection method can be used based on these initial values. With observations of real data, it seems likely that initial pay levels will vary across performance categories, reflecting past pay policies, demographics, and performance distributions. Although quite easy to

\footnotetext{
${ }^{2}$ The Bureau of Labor Statistics provides a wealth of information on hourly earnings for diverse groups and occupations (see BLS, 2002, Table 3). We used the average hourly earnings and weekly hours of all white-collar occupations, excluding sales jobs. The most recent information shows that white-collar, full-time employees (excluding sales) earned an average hourly wage of \$21.65 and worked an average of 39.4 hours per week in 2001. Based on the 29th Annual Report on the '2002-2003 Total Salary Increase Budget Survey (Worldatwork, 2002), salary increases averaged 3.9\% for exempt salaried employees in 2002, and is projected to increase $4.1 \%$ for 2003. This led us to use an estimated hourly wage of $\$ 23.42$, for a total salary for 2003 of $\$ 47,983$. Note again that anyone employing the methods described in this paper can simply enter the data from other sources, such as their own company's data. The value we chose was intended to capture a broad, generalizable sample. More importantly, it is intended to be a reasonable estimate to help illustrate our technique.
} 
observe in practice, pay-performance distributions are likely quite variable, so no obvious method exists to simulate them for our example. Our decision to begin with a uniform pay distribution across categories simplifies the presentation but does not otherwise reduce the generalizability of our approach.

\section{Step 2: Determine Turnover Probabilities}

The second step in the making explicit of organizational characteristics and assumptions (i.e., the first major phase in Figure 1 ) is to estimate the probability of separation at each performance level for each pay strategy. This step defines the key link between performance-based pay and workforce composition. For practitioners, this may represent the most novel element of the model, yet, we believe it is quite feasible. We describe several methods for estimating these probabilities.

Estimation wing existing research literature: Perhaps the most straightforward approach is to refer to existing empirical findings. For our hypothetical example, we use the performance level/pay strategy specific separation results generated by Trevor et al. (1997). Professionals employing utility analysis likely would prefer to access separation probabilities from a study of an employee population that resembled their own employees in terms of occupations, industry, and demographics. To date, however, the Trevor et al. (1997) study is the only published work from which the performance level/pay strategy specific separation probabilities can be estimated. Although future research providing such information for different employee populations would be helpful, in their absence, the Trevor et al. (1997) results offer a useful starting point.

Estimation using organizational data: A second option for generating the performance level/pay strategy specific separation probabilities that are necessary for the cost-benefit analysis would be for professionals to estimate them using their own organization's data. In most companies, separation rates are customarily calculated for entire job categories and are seldom broken down by performance levels. Even when separation rates are reported by performance levels, they are rarely further broken down to reflect pay growth. Yet, if yearly individual-level information on performance, pay level, and separation is available, it can rather easily be converted into the required separation probabilities estimates.

First, professionals can compute each employee's average pay growth and average employee performance over a specified time period (e.g., over the last 3 years). These relatively continuous data can then be used to slot employees into performance level/pay strategy categories, such as Table 1's 27 categories that were created from all combinations of three pay strategies and nine performance levels. 
This approach would be repeated for all appropriate performance level and pay growth combinations, thus yielding counts of employees that fit each category. After compiling these counts, the second step would be simply to divide each category's number of voluntary separations by the number of employees in that category. This would yield the estimates of the separation probabilities specific to each performance level/pay strategy combination that are necessary for conducting the cost-benefit analysis of performance-based pay.

Although relatively simple to describe, estimating category-specific separation probabilities from one's own organization involves two potentially difficult hurdles. First, to estimate the separation probabilities with any degree of reliability, there must be an adequate number of employees in the categories of interest. If the number of employees in a given category is low, then the resultant average rate of turnover may be strongly influenced by sampling error rather than reflecting an accurate estimate of that category's true turnover likelihood (e.g., a category with one employee mandates an unrealistic separation probability estimate of either one or zero). Thus, the HR professional or I-O psychologist must be working with relatively few categories and/or with large employee populations. A second serious problem with the approach described above is that it will produce separation probabilities that are likely to be confounded by other factors that are related to turnover, performance, and pay growth, such as pay level, age, gender, and tenure with the organization. Hence, though computing performance level/pay strategy specific separation probabilities for one's own organization is relatively simple, its value may be limited.

Fortunately, two statistical methods are available for dealing with the confounding and employee-per-category problems. Although both of these methods require a statistical package and reasonable statistical sophistication, I-O psychologists may well have been exposed to one or both of the methods. If not, their training still may well have provided them with a methodological foundation sufficient to allow them to learn the techniques, particularly with the advances in user-friendly statistical software. Alternatively, HR professionals or I-O psychologists could simply hire a consultant to assist with the analyses.

Logistic regression and survival analysis can be used to estimate separation probabilities. Both explicitly account for the potential confound described above by statistically controlling for the effects of these other variables. The analyses yield partial coefficients that are net of the effects of the potentially confounding variables. The partial coefficients are then used to compute separation probabilities needed to conduct the cost-benefit analysis. Both methods also exploit the full range of the relatively continuous salary growth and performance data, rather than requiring preestablished 
categories that necessarily result in a loss of information. Logistic regression estimates the probability of separation over a specified time period. Survival analysis (Kalbfleisch \& Prentice, 1980) computes the probability of survival (i.e., not separating) over a specified timespan and accounts for the length of time an individual stays before leaving the organization. In other words, survival analysis specifically models how long an individual remains with an employer before leaving, whereas logistic regression models whether a person leaves or not. Although both methods are appropriate for estimating the separation probabilities specific to the performance 1eveUpay strategy combinations of interest, each offers advantages under certain circumstances (for a complete discussion of this issue, see Morita, Lee, \& Mowday, 1993). The Appendix describes the use of survival analysis to calculate the required separation probabilities that are specific to each of our performance level/pay strategy combinations.

Estimated separation probabilities for the example: For our example, we used the survival analysis results reported in Trevor et al. (1997), which estimated a survival model from data on a sample of exempt employees in one organization. The analysis produced a mathematical function describing survival probabilities as a function of salary growth and performance, which we present in the Appendix. Substituting a specific salary growth amount and performance level into the equation produces an estimated survival probability that is appropriate for that performance level and salary growth combination. Thus, we used the equation reported in Trevor et al.'s (1997) Table 4 (p. 54) to compute the separation probability (1.0 minus the survival probability), for each performance category under each pay strategy, at the end of our example's 4-year period. The estimated separation probabilities are presented in the top part of Table 2.

We caution that our use of the Trevor et al. (1997) survival analysis provides reasonable separation probability estimates, rather than definitive ones. It is certainly probable that other factors could also influence the probability of turnover. For example, equity theory suggests that even when high performers receive the same pay increase (such as under Pay Strategy 2 and Pay Strategy 3), their turnover likelihoods may differ as a function of how referent others (e.g., low performers) are compensated. Our approach does not take this into consideration. Thus, the reader should keep in mind the imperfections associated with relying on any single study, model of turnover, or data set to estimate turnover probabilities. 
TABLE 2

Turnover Probabilities and Estimate Number of Retained and Replaced Employees

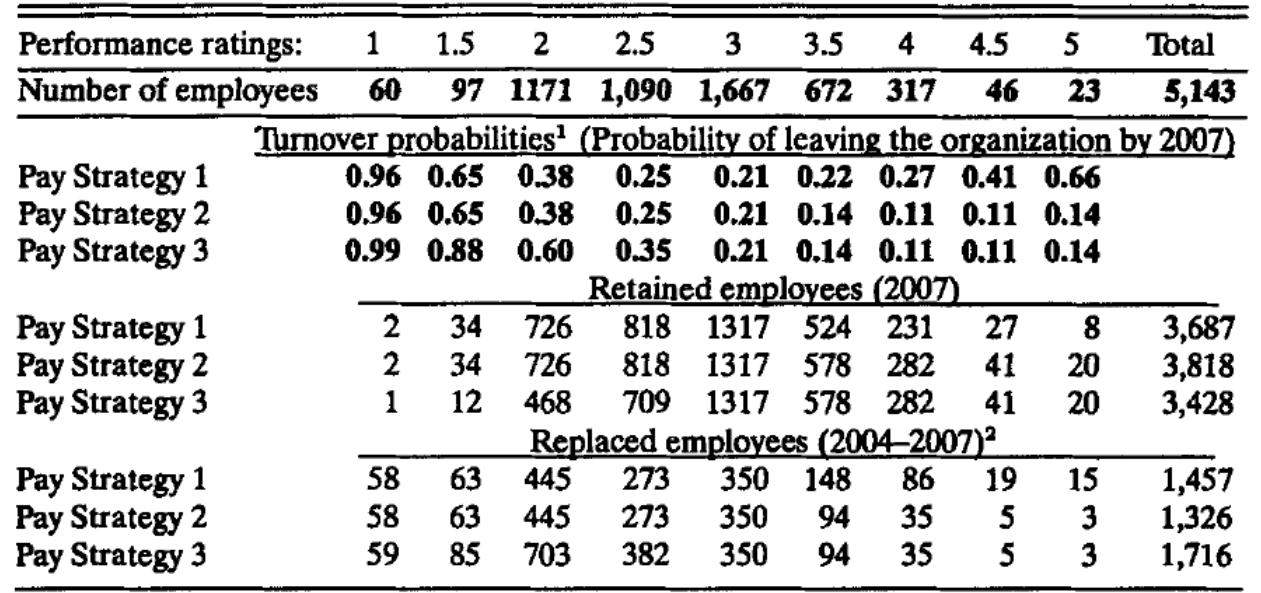

Note: Data provided by the user are in bold.

1 These values were based on analyses from the Trevor et al. (1997) study. Those performing their own analyses would need to complete the table with their own companyspecific data, or use approximations from the Trevor et al. results. See the Appendix for how we used the Trevor et al. results to obtain our values above.

${ }^{2}$ Recall that we are evaluating the effects of the different pay policies going into effect at the end of 2004. Thus, although our data are based on the state of the workforce at the end of 2003, we are evaluating the effects of the programs in 2004-2007.

\section{Step 3: Determine Performance Distribution and Number of Separations}

So far, we have established the pay increase that individuals in each performance level will receive under the different pay policies and we have subsequently established the separation probabilities for each performance level/pay strategy category. Next, we need to project the number of separations in each performance level/pay strategy category over time. We specified our initial hypothetical employee group (those at the end of year 2003) to mirror in size and performance distribution the 5,143 employees analyzed by Trevor et al. (1997), which is shown in Table 2 (in actual organizations, the initial number of employees in each performance category would be identified through a straightforward count). We then multiplied the initial number of employees in each performance level/pay strategy category by the appropriate separation probability. Table 2 presents the resultant category-specific numbers of employees that separated (and will need to be replaced) and employees retained.

At this point, a traditional analysis of total separations would likely lead to a decision to adopt Pay Strategy 2, the moderately aggressive policy through which performers above the midpoint receive higher pay increases. As Table 2 indicates, the number of separations over the 4-year analysis period is 1,326 for Pay Strategy 2, 1,457 for Pay Strategy 1, and 1,716 for Pay Strategy 3. Based only on separation 
rates, Pay Strategy 3 seems the least attractive policy. However, such conclusions are simplistic and superficial from a cost/benefits perspective; a more sophisticated and meaningful inference regarding the implications of the three pay strategies requires an analysis incorporating critical financial data.

\section{Estimating the Cost of Pay-for-Performance Plans}

\section{Step 4: Determine Movement Costs}

In Steps 1 through 3, we specified the pay-for-performance options, the estimated separation probabilities, and the subsequent numbers of separations and necessary replacements from each performance level/pay strategy combination. Hence, one key financial outcome to be considered is the projected cost of employee movements into and out of the workforce under each pay policy. As we see in Table 2, relative to the retention effects of simply providing everyone with the same salary increase (Pay Strategy I), Pay Strategy 2 reduces overall separations, but Pay Strategy 3 increases them. We next translate these projected separations and replacements into financial costs.

We refer to the combined costs of employee separations and replacement acquisitions as movement costs. These costs include direct expenses, such as separation costs (e.g., exit interview, separation pay), replacement costs (e.g., advertising, travel expenses, interviewing and testing candidates), and training costs (e.g., informational literature costs, paying trainers). Movement costs also include indirect expenses, such as the lower productivity of new employees as they learn the job, time spent by managers having to supervise new employees more directly, and diminished productivity of veteran employees as they mentor and help new employees (Cascio, 2000). Although such costs are not standard elements of traditional accounting systems, organizations increasingly employ software and reporting algorithms that calculate such metrics as turnover costs, costs per hire, and so forth. If these are available, one can simply multiply the relevant cost by the number of separations and/or replacements that emerge under each pay strategy.

Data available to calculate movement costs vary widely across companies. When movement costs are not readily available from the organization, one can turn to research. For example, Solomon (1988) suggested that movement costs range from 1.5 to 2.5 times the annual salary paid for a job (Solomon, 1988), and Johnson (1995) suggested that movement costs range from $93 \%$ to $200 \%$ of the position's salary. In our example, we estimated the movement cost associated with each separation as two times the average salary of all employees in the year of the separation (note that average salary will vary according to pay strategy). We also assumed that each separation is replaced, and, thus, we 
combined all separation and acquisition costs into a single estimate labeled movement costs. Should replacement not be expected, such as during a downsizing, separation cost estimates should be applied to the number of separations, and replacement acquisition costs should be applied to the number of replacements (Boudreau \& Berger, 1985).

Table 3 provides the necessary information to estimate movement costs for our example. At the top of the table is the workforce's average salary in 2003 and in 2007 under each of the three pay strategies. As noted above, we multiplied this salary by 2.0 to estimate the average movement costs for each separation, which is shown for years 2003 and 2007. We then subtracted the 2003 average movement cost from the 2007 average movement cost and divided by four to get yearly movement cost increase, which we added to the 2003 average movement cost to get the 2004 average movement cost. This was added to the 2007 average movement cost and the sum was divided by two to compute the average (2004-2007) movement cost per separation. Table 3 also provides the total projected number of separations/replacements from 2004 to 2007, which were calculated in Table 2. Total movement costs for each pay strategy over the 4-year period were then calculated by multiplying each pay strategy's total number of projected separations/replacements by each pay strategy's average movement cost per separation/replacement.

Table 3's total estimated movement costs were $\$ 154.67$ million, $\$ 142.05$ million, and $\$ 181.80$ million for Pay Strategies 1, 2, and 3, respectively. Compared to Pay Strategy 1 (giving equal pay increases to everyone), the turnover reduction associated with the policy of linking pay and performance for high performers (Pay Strategy 2) saves \$12.61 million in movement costs over four years. Linking pay and performance for both high and low performers (Pay Strategy 3), however, creates additional separations among low performers and, thus, incus 4-year movement costs of $\$ 27.13$ million and \$39.75 million more than those incurred through Pay Strategies 1 and 2, respectively. 
TABLE 3

Estimated 4-Year Movement Costs Under Different Pay Strategies

\begin{tabular}{|c|c|c|c|}
\hline & Pay Strategy 1 & Pay Strategy 2 & Pay Strategy 3 \\
\hline \multicolumn{4}{|l|}{ Average salary } \\
\hline 2003 & $\$ 47,983$ & $\$ 47,983$ & $\$ 47,983$ \\
\hline 2007 & $\$ 56,133$ & $\$ 56,914$ & $\$ 55,966$ \\
\hline $\begin{array}{l}\text { Movement cost multiplier } \\
\text { (cost of separation as multiple of salary; } \\
\text { same for all three pay strategies) }\end{array}$ & 2.0 & & \\
\hline \multicolumn{4}{|l|}{ Average movement costs (per separation) } \\
\hline 2003 & $\$ 95,966$ & $\$ 95,966$ & $\$ 95,966$ \\
\hline 2007 & $\$ 112,266$ & $\$ 113,828$ & $\$ 111,932$ \\
\hline Yearly increase in average movement cost & $\$ 4,075$ & $\$ 4,466$ & $\$ 3,992$ \\
\hline 2004 Average movement cost & $\$ 100,041$ & $\$ 100,432$ & $\$ 99,958$ \\
\hline Average movement cost (2004-2007) & $\$ 106,154$ & $\$ 107,130$ & $\$ 105,945$ \\
\hline Number of separations & 1,457 & 1,326 & 1,716 \\
\hline Total movement costs ${ }^{1}$ & $\$ 154,666,378$ & $\$ 142,054,380$ & $\$ 181,801,620$ \\
\hline
\end{tabular}

Note: Data provided by the user are in bold.

1 Total movement costs were calculated assuming a linear growth in movement costs and an equal number of separations in each year. Thus, total movement costs could be calculated as the number of separations times the average 2004-2007 movement costs. For simplicity, we assumed a constant rate of movement cost increase over time. This could easily be modified if an organization projected very significant increases or decreases in costs per movement in a given year, but such large discontinuities seem unlikely.

Some of these costs would be evident with standard accounting tools, to the extent that they represent "out-of-pocket" costs such as fees to search firms or consultants providing exit interviews. However, as mentioned above, many of these costs (e.g., staff time spent in processing separations and acquisitions) are "opportunity costs," and only a portion of these savings (costs) would be recorded by the accounting system. Thus, our analytical approach offers the advantage of a more complete cost analysis for incentive pay strategies. Still, movement costs represent only one of the crucial financial implications of using pay-for-performance to manage performance and turnover. Hence, we next address the pay strategies' substantial implications for differences in costs associated with pay levels, benefits, and other service costs.

Step 5: Estimate Future Service Costs

Service costs are the total costs required to retain and support the work force, and, thus, include pay and benefits (Boudreau \& Berger, 1985), the latter of which is typically the largest service cost component other than pay. In some cases, service costs may vary with employee performance. For example, there may be significant bonuses or stock options, or higher performers may use significantly more materials or resources than lower performers. In these cases, which would tend to be of more relevance in executive populations, such variability in service costs should also be taken into account. 
Absent such factors, estimating service costs simply involves adjusting projected salary levels upward to reflect additional service costs (i.e., benefits), multiplying the resulting values by the number of employees in each year, and summing the products across years. Because we define total service costs as salary plus benefits in our example, we estimate each year's service costs by estimating the ratio of total remuneration (employee benefits plus salary) to salary, and then multiplying this ratio by projected salary levels under each pay policy.

In Table 3, we had established, for each pay strategy, the average salary levels for the full work force in 2003 and 2007. Because we assumed that benefits were $37 \%$ of salary (US. Department of Labor, 2001), we multiplied Table 3's average salary levels by 1.37 to reflect the 2003 and 2007 average service costs for each pay strategy (see Table 4). Using the assumption that service costs increased linearly from 2003 to 2007, we then computed, for each of the three pay strategies, (a) the average service cost increase (2007 service cost minus 2003 service cost, divided by four), (b) 2004 service cost (2003 service cost plus the average service cost increase), (c) the average 2004-2007 service cost (2004 service cost plus 2007 service cost, divided by two), and (d) the total 2004-2007 service cost (average 2004-2007 service cost times four, the number of years in our simulation, times 5,143, the total number of employees in each year).

An implication of our decision to use the workforce average service costs to estimate total service costs is that it implicitly assumes that replacement employees will be paid at the average level of the workforce they enter. The framework of this model can certainly accommodate other assumptions (e.g., stronger pay-performance links will attract better performers who will be paid more), and would allow practitioners to incorporate such data when appropriate. We adopted the workforce-average assumption for simplicity.

Pay Strategy 2 yielded the highest service costs; it is projected to cost $\$ 13.76$ million more than Pay Strategy 1 (no performance-pay relationship). Under Pay Strategy 2, pay is always equal (for performers at or below the performance midpoint) or higher (for performers above the midpoint) than in Pay Strategy 1. Pay Strategy 3 raises the pay for higher performers, but also lowers pay for lower performers, resulting in costs of $\$ 2.94$ million less over 4 years than Pay Strategy 1 , and $\$ 16.70$ million less than Pay Strategy 2.

Service costs (i.e., pay and benefits) are highly visible to standard accounting systems. In fact, one could argue that they are the most visible elements of human capital in standard accounting. Thus, if standard accounting were used to evaluate these pay policies, the costs shown in Table 4 would likely be quite evident, and would perhaps suggest an argument for Pay Strategy 3 to organizational 
constituents who rely on accounting information for their decisions. Given that the movement costs analysis suggested Pay Strategy 3 as the least economical approach, however, it is clear that relying on only a single type of cost information may well provide an inaccurate basis for a decision. When we do aggregate the total movement and total service cost data from Tables 3 and 4, we see that Pay Strategy 3 is the most expensive, costing over $\$ 23$ million more than Pay Strategy 2 and over \$24 million more than Pay Strategy 1.

\section{TABLE 4}

Estimated 4-Year Service Costs Under Different Pay Strategies

\begin{tabular}{lrrr}
\hline & Pay Strategy 1 & Pay Strategy 2 & Pay Strategy 3 \\
\hline $\begin{array}{l}\text { Average service cost multiplier } \\
\text { (per employee) }\end{array}$ & 1.37 & 1.37 & 1.37 \\
$\begin{array}{l}\text { Average service cost } \\
2003\end{array}$ & & & \\
2007 & $\$ 65,737$ & $\$ 65,737$ & $\$ 65,737$ \\
Yearly increase in service costs & $\$ 76,902$ & $\$ 77,972$ & $\$ 76,673$ \\
2004 Average service cost & $\$ 2,791$ & $\$ 3,059$ & $\$ 2,734$ \\
Average service cost (2004-2007) & $\$ 68,528$ & $\$ 68,796$ & $\$ 68,471$ \\
Total service costs (2004-2007) & $\$ 1,495,892,980$ & $\$ 1,509,655,648$ & $\$ 1,492,951,184$ \\
\hline
\end{tabular}

Note: Average service cost per employee is assumed to equal 1.37 times Table 3's average salary under each pay strategy. Total costs were calculated assuming a linear growth in service costs. Thus, it was estimated to equal the number of employees times the number of years times the average service costs (2004-2007).

Data provided by the user are in bold.

Consequently, from a cost-based perspective, we might conclude that undertaking an aggressive pay-for-performance system to "win the talent war" is not worth the investment. We instead caution that such an inference (and any decisions based on it) is at the least premature and is potentially detrimental to the organization. High performers provide greater value than do low performers, and any assessment of an HR program that differentially affects the performance distribution of the workforce must account for this. HR investments must be examined for both their "efficiency" and "effectiveness" (Boudreau \& Ramstad, 2003b). Hence, having addressed the movement and service costs implications of the three pay strategies' effects on turnover, we next turn to the strategies' implications for workforce's value, an often overlooked but absolutely essential consideration when assessing the financial practicality of human resource interventions. 


\section{Estimating the Value of Pay-for-Performance Plans}

\section{Step 6: Determine Service Value}

Although our analyses have focused on the cost implications of the pay-for-performance strategies, such strategies also can produce value through the elimination of poor performers (and their subsequent replacement by average performers), and, in particular, the retention of high performers, whose retention is especially sensitive to pay-for-performance effects (Trevor et al., 1997). Moreover, when differences in individual performance are high (Le., when a high performer is worth much more to the organization than an average performer), retaining top employees and eliminating poor employees may yield value that far outweighs the associated costs (Boudreau \& Berger, 1985; Boudreau, 1991; Boudreau \& Ramstad, 1999; 2003a; 2003b).

To examine the potential effects of performance-based pay on workforce value, we need to estimate the dollar value of individual performance variation. This will allow us to estimate the effect that changes in the workforce's performance distribution will have on workforce value. Our data provide estimates of changes in the performance ratings, so we must convert ratings to dollar values. This conversion method requires two components (Boudreau \& Berger, 1985): (a) the dollar value of the average performance level; and (b) the incremental value of deviations from that average performance level. ${ }^{3}$

We employed the Schmidt and Hunter (1983) approach, which assumes that the value of the average performance level would equal 1.754 times the average wage at that level. For the 2003 work force, we multiplied Table 3's average salary of $\$ 47,983$ by 1.754 to obtain a service value of $\$ 84,162$ per person. For the 2007 work force, consistent with the estimate of average service costs above, we estimated average salary as that which would have been produced by four years of average salary increases, beginning in 2004. As noted in Table 3, the average 2007 salary under Pay Strategy 1, which allocates average salary increases across the performance distribution, is estimated to be $\$ 56,133$. Multiplying this salary by 1.754 produces an average work force value estimate of $\$ 98,457$ per person.

\footnotetext{
${ }^{3}$ There is no single accepted method of estimating the dollar value of average performance among workers or applicants. Some research has suggested that average performance value can be estimated equal to the average compensation of the work p u p (Boudreau, 1991, p. 654; Raju, Burke, \& Normand, 1990. p. 9). However, it seems unlikely that average-performing employees produce only enough value to offset their direct wage costs. Considering the other service costs that are incurred, and the need for organizations to obtain a positive return on costs, a higher level of average service value seems likely. Based on an analysis of wage and productivity estimates in the national income accounts of the United States, Schmidt and Hunter (1983) proposed assuming that the ratio of average dollar value to average wage is approximately 1.754 .
} 
These 2003 and 2007 average service value estimates are shown in "average service value" section of Table 5.

TABLE 5

Computations for Estimating Individual Service Value at Each Performance Level

\begin{tabular}{|c|c|c|c|c|c|c|c|c|c|}
\hline Performance ratings: & 1 & 1.5 & 2 & 25 & 3 & 35 & 4 & 45 & 5 \\
\hline $\begin{array}{l}\text { Number of employees } \\
\text { Mean performance } \\
\text { Standard dev. of performance }\end{array}$ & 60 & $\begin{array}{r}97 \\
2.764 \\
0.668\end{array}$ & 1,171 & 1,090 & 1,667 & 672 & 317 & 46 & $\overline{23}$ \\
\hline$z$-Score of performance ratings & -2.641 & -1.892 & -1.144 & -0.395 & 0.353 & 1.102 & 1.850 & 2.599 & 3.347 \\
\hline \multicolumn{10}{|c|}{ Average service value (assumed to equal $1.754 \times$ average salary) } \\
\hline 2003 & $\$ 84,162$ & $\$ 84,162$ & $\$ 84,162$ & $\$ 84,162$ & $\$ 84,162$ & $\$ 84,162$ & $\$ 84,162$ & $\$ 84,162$ & $\$ 84,162$ \\
\hline 2007 & $\$ 98,457$ & $\$ 98,457$ & $\$ 98,457$ & $\$ 98,457$ & $\$ 98,457$ & $\$ 98,457$ & $\$ 98,457$ & $\$ 98,457$ & $\$ 98,457$ \\
\hline Incremental service value $S D_{y}=$ & 0.30 & & & & & & & & \\
\hline 2003 & $-\$ 38,017$ & $-\$ 27,235$ & $-\$ 16,468$ & $-\$ 5,686$ & $\$ 5,081$ & $\$ 15,863$ & $\$ 26,631$ & $\$ 37,412$ & $\$ 48,180$ \\
\hline $\begin{array}{l}2007 \\
\text { Incremental service value } S D_{y}=\end{array}$ & $i^{-\$ 44,474}$ & $-\$ 31,861$ & $-\$ 19,265$ & $-\$ 6,652$ & $\$ 5,944$ & $\$ 18,558$ & $\$ 31,154$ & $\$ 43,767$ & $\$ 56,363$ \\
\hline 2003 & $-\$ 76,034$ & $-\$ 54,470$ & $-\$ 32,936$ & $-\$ 11,372$ & $\$ 10,163$ & $\$ 31,726$ & $\$ 53,261$ & $\$ 74,825$ & $\$ 96,359$ \\
\hline 2007 & $-\$ 88,948$ & $-\$ 63,722$ & $-\$ 38,530$ & $-\$ 13,304$ & $\$ 11,889$ & $\$ 37,115$ & $\$ 62,308$ & $\$ 87,534$ & $\$ 112,726$ \\
\hline Incremental service value $S D_{y}=$ & 0.90 & & & & & & & & \\
\hline 2003 & $-\$ 114,051$ & $-\$ 81,705$ & $-\$ 49,403$ & $-\$ 17,058$ & $\$ 15,244$ & $\$ 47,590$ & $\$ 79,892$ & $\$ 112,237$ & $\$ 144,539$ \\
\hline 2007 & $-\$ 133,423$ & $-\$ 95,583$ & $-\$ 57,795$ & $-\$ 19,955$ & $\$ 17,833$ & $\$ 55,673$ & $\$ 93,461$ & $\$ 131,301$ & $\$ 169,089$ \\
\hline \multicolumn{10}{|c|}{ Total individual service value $\left(S D_{v}=30 \%\right)^{1}$} \\
\hline 2003 & $\$ 46,145$ & $\$ 56,927$ & $\$ 67,694$ & $\mathbf{\$ 7 8 , 4 7 6}$ & $\$ 89,243$ & $\$ 100,025$ & $\$ 110,793$ & $\$ 121,574$ & $\$ 132,342$ \\
\hline 2007 & $\$ 53,983$ & $\$ 66,596$ & $\$ 79,192$ & $\$ 91,805$ & $\$ 104,401$ & $\$ 117,015$ & $\$ 129,611$ & $\$ 142,224$ & $\$ 154,820$ \\
\hline \multicolumn{10}{|c|}{ Total individual service value $\left(S D_{v}=60 \%\right)$} \\
\hline 2003 & $\$ 8,128$ & $\$ 29,692$ & $\$ 51,226$ & $\$ 72,790$ & $\$ 94,325$ & $\$ 115,888$ & $\$ 137,423$ & $\$ 158,987$ & $\$ 180,521$ \\
\hline 2007 & $\$ 9,509$ & $\mathbf{\$ 3 4 , 7 3 5}$ & $\$ 59,927$ & $\$ 85,153$ & $\$ 110,346$ & $\$ 135,572$ & $\$ 160,765$ & $\$ 185,991$ & $\$ 211,183$ \\
\hline \multicolumn{10}{|c|}{ Total individual service value $\left(S D_{v}=90 \%\right)$} \\
\hline 2003 & $-\$ 29,889$ & $\$ 2,457$ & $\$ 34,759$ & $\$ 67,104$ & $\$ 99,406$ & $\$ 131,752$ & $\$ 164,054$ & $\$ 196,399$ & $\$ 228,701$ \\
\hline 2007 & $-\$ 34,966$ & $\$ 2,874$ & $\$ 40,662$ & $\$ 78,502$ & $\$ 116,290$ & $\$ 154,130$ & $\$ 191,918$ & $\$ 229,758$ & $\$ 267,546$ \\
\hline
\end{tabular}

Note: Data provided by the user are in bold.

${ }^{1}$ Total individual service value is computed as average service value plus incremental service value, shown in the top portion of this table.

For the second component necessary to estimate the value associated with each employee, we needed an estimate for the value of each performance level above and below the average. Combined with the estimate for the average value of individuals' performance, this will allow us to calculate the value of each of the nine performance levels in both 2003 and 2007. In this study, and probably characteristic of most organizations, we had no direct estimates of the dollar value of particular performance levels. Hence, we used an estimation approach typical of utility analysis studies (e.g., Boudreau, 1991; Boudreau \& Ramstad, 2003b). Utility analysis typically employs an estimate of the value of a one-standard-deviation difference in employee value, referred to as $\mathrm{SD}_{\mathrm{y}}$ with $\mathrm{SD}_{\mathrm{y}}$ often approximated as equal to a given percentage of salary (Boudreau, 1991; Cascio, 2000). Thus, someone who performs one standard deviation above average (i.e., someone who is in the 84th percentile of performance) is estimated to be worth more than an average performer by a value equal to $\mathrm{SD}_{\mathrm{y}}$. Using the $\mathrm{SD}_{\mathrm{y}}$ term, we can compute the value of each performance category relative to the average. 
A recurring problem with using $\mathrm{SD}_{\mathrm{y}}$ is that it is unlikely to be estimated precisely (Boudreau, 1991; Cascio, 2000). Furthermore, its impact on final estimates of the value of a utility estimate is often quite significant (Boudreau, 1991). Thus, we investigated three potential values. As a very conservative approach, we assumed that $\mathrm{SD}_{\mathrm{y}}$ would equal $30 \%$ of average salary. This is substantially less than Schmidt and Hunter's (1983) 40\% recommendation, which has been characterized as a conventional benchmark (Becker \& Huselid, 1992), a safe estimate (Schmidt, Hunter, Outerbridge, \& Trattner, 1986), and a conservative estimate (Judiesch, Schmidt, \& Mount, 1992). We also used 60\% of average salary as a somewhat conservative estimate, and we used $90 \%$ of average salary as what we believe to be a more realistic estimate. ${ }^{4}$ In other words, our three estimates suggest that an employee performing better than $84 \%$ of the employee population is worth $30 \%$ of salary, $60 \%$ of salary, or $90 \%$ of salary more to the organization than an average performer (i.e., someone performing at the 50th percentile) in the same job.

In order to move from these $\mathrm{SD}_{\mathrm{y}}$ estimates to estimates of each employee's service value, we first used the observed distribution of employee performance to compute the standardized z-score corresponding to each of the nine performance ratings. This transformation, accomplished through subtracting the mean performance score from each performance category rating and then dividing by the performance standard deviation, produces a performance distribution with a mean of zero and a standard deviation of one. For example, performance category 1.5 received a z-score of -1.89 through subtracting the average performance rating of 2.764 from 1.5 and dividing by the standard deviation of 0.668. The z-scores, which represent the number of standard deviations that each performance category rating deviates from the performance mean, are listed in the fifth row of data in Table 5.

We assumed that the $z$-scores associated with each raw performance score would remain constant from 2003 to 2007 . That is, although the actual distribution of workers across performance categories changes from 2003 to 2007, we assumed that the value of performance at each performance level did not change. For example, a performance rating of 4 in 2003, which was 1.850 standard deviations above the mean in 2003, provided value to the employer equal to mean performance's value plus the product of 1.850 and $\mathrm{SD}_{\mathrm{y}}$. We assumed, regardless of the actual number of employees who received a score of 4 in 2007, the financial value of an individual with a performance rating of 4 in that year would be equal to 2007 mean performance's value plus the product of 1.850 and $\mathrm{SD}_{\mathrm{y}}$.

\footnotetext{
${ }^{4}$ Support of the $90 \%$ approach is provided by Becker and Huselid (1992) who found direct observations of fell in the $74 \%$ to $100 \%$ of mean salary range. Moreover, because researchers generally contend that $\mathrm{SD}_{\mathrm{y}}$ increases as job complexity increases (e.g., Judiesch et al., 1992), our 30\% and 60\% SD values would appear to have additional support as conservative estimates given our sample of all exempt hires in a large company.
} 
For 2003, we estimated average salary as $\$ 47,983$ (from Table 1), producing Sa, estimates of $\$ 14,395$ (i.e., $0.3 \times \$ 47,983$ ), $\$ 28,790$ (i.e., $0.6 \times \$ 47,983$ ), and $\$ 43,185$ (i.e., $0.9 \times \$ 47,983$ ) for the $30 \%$, $60 \%$, and $90 \% \mathrm{SD}_{\mathrm{y}}$ scenarios, respectively. For 2007 , estimated average salary was $\$ 56,133$ (from Table 1), producing, at the $30 \%, 60 \%$, and $90 \% \mathrm{SD}_{\mathrm{y}}$ scenarios, estimated $\mathrm{Sa}$, levels of $\$ 16,840$ (i.e., $0.3 \mathrm{x}$ $\$ 56,133$ ), $\$ 33,680$ (i.e., $0.6 \times \$ 56,133$ ), and $\$ 50,520$ (i.e., $0.9 \times \$ 56,133$ ). Multiplying these $\mathrm{SD}_{\mathrm{y}}$ estimates (i.e., the appropriate dollar value of a one standard deviation performance difference) by the z-scores (i.e., the number of standard deviations the performance category is from the mean) produced the "incremental" (beyond the average) dollar values corresponding to each performance rating level for each $\mathrm{SD}_{y}$, assumption (see Table 5). Thus, under the 60\% assumption in 2007, an employee at performance level 5.0 is worth $\$ 112,726$ more than an average employee (i.e., $\$ 56,133 \times 0.60 \times 3.347$ ). The sums of the average service values for the workforce and the incremental service values for each performance category produced the individual service values for each performance category that are reported in the bottom section of Table 5. Thus, the last six lines of data in Table 5 represent, for each unique combination of performance level (1.0 - 5.0 at half point intervals), year (2003 and 2007), and SD, scenario (30\%, 60\%, and go\%), the individual service value for each employee.

With individual service values determined for both 2003 and 2007, we can now compute the total service value for the workforce under each of the three pay strategies. For 2003 (for all three pay strategies), we calculated the total service value of the workforce by multiplying each performance category's individual service value by the corresponding quantity of employees in the performance category, and adding the products. Thus, for example, Table 5's individual service value of $\$ 115,888$ for $\mathrm{SD}_{\mathrm{y}}=60 \%$ and performance $=3.5$ in 2003 is multiplied by 672 (the number of employees in that performance category) to yield the $\$ 77,876,736$ figure in Table 6 (under $\mathrm{SD}_{\mathrm{y}}=60 \%$ and performance $=$ 3.5). This $\$ 77,876,736$ is then added to the similarly computed values for the other eight performance categories to produce, when $\mathrm{SD}_{\mathrm{y}}=60 \%$, Table 6's total 2003 service value of $\$ 432,351,857$. This is our estimate of what the workforce is worth to the employer in 2003 under the assumption that being one standard deviation above average in performance is worth $60 \%$ of an average performer's salary. We note that total service values are the same in 2003 regardless of pay strategy (though they do differ across $\mathrm{SD}_{\mathrm{y}}$ assumptions) because the three pay strategies had yet to result in the different performancespecific turnover patterns that begin in 2004.

For 2007 , calculation of the total service value of the workforce is slightly more complex, as the computations for those employees retained over the 4-year analysis differ from the computations required for those hired as replacements during the 4-year period. For the retained employees, 2007 
total service value calculation closely resembles the approach to 2003, where Table 5's 2003 individual service values for each $\mathrm{SD}_{\mathrm{y}}$ level and performance category combination were multiplied by the quantity of retained employees for each performance category and these products were summed. In 2007, however, the three pay strategies' different effects on performance-specific turnover result in pay strategy-specific numbers of retained employees in each performance category. Consequently, we need to conduct the individual service value by employee quantity multiplications separately for each pay strategy to get the 2007 estimates. Thus, Table 5's 2007 individual service values for each SD, level and performance category combination were multiplied by the quantity of retained employees for each performance category under each pay strategy and these products were summed. For example, Table 5 's individual service value of $\$ 129,611$ for $\mathrm{SD}_{\mathrm{y}}=30 \%$ and performance $=4.0$ in 2007 is multiplied by 231,282 , and 282 (the number of retained employees in that performance category under the three pay strategies, as listed in Table 7) to yield the $\$ 29,940,141, \$ 36,550,302$, and $\$ 36,550,302$ figures in Table 7 (under $\mathrm{SD}_{\mathrm{y}}=30 \%$, performance $=4.0$, and Pay Strategies 1, 2, and 3, respectively). Thus, the final nine rows of data in Table 7 chronicle, for each $\mathrm{SD}_{\mathrm{y}}$ and pay strategy combination, the combined service value of all retained employees in 2007 at each performance level. The final column for each of these nine rows provides total service values across performance categories.

Having computed 2007 service value for retained employees, we next address the 2007 value of those employees hired to replace the employees that separated during the 2004-2007 window. These replacement employees were assumed to have an individual service value equal to the average individual service value of retained employees under Pay Strategy 1 for each of the $\mathrm{SD}_{\mathrm{y}}$ assumptions. Thus, for example, Table 8's average individual replacement employee service value of $\$ 101,594$ when $\mathrm{SD}_{\mathrm{y}}=60 \%$ was computed by dividing Table 7 's total retainee service value of $\$ 374,575,510$, which is under Pay Strategy 1 with $\mathrm{SD}_{\mathrm{y}}=60 \%$, by 3,687, which is Table 7's total retainees under Pay Strategy 1. We note that using Pay Strategy 1 's retainee service value for all replacements assumes that the recruiting effectiveness and job performance of replacement employees are not affected by the compensation system. Because the average service value of retained employees under Pay Strategies 2 and 3 is greater than the average service value of employees retained under Pay Strategy 1, this provides a conservative estimate of replacement service value under the two pay strategies with payfor-performance links. The total service value of replacement employees for each pay strategy and $\mathrm{SD}_{\mathrm{y}}$ combination is equal to the pay strategy-specific number of replacements times the $\mathrm{SD}_{\mathrm{y}}$ specific average service value. These totals are reported in the bottom three rows of data in Table 8. 
TABLE 6

Computing Total Service Value (2003 Employees)

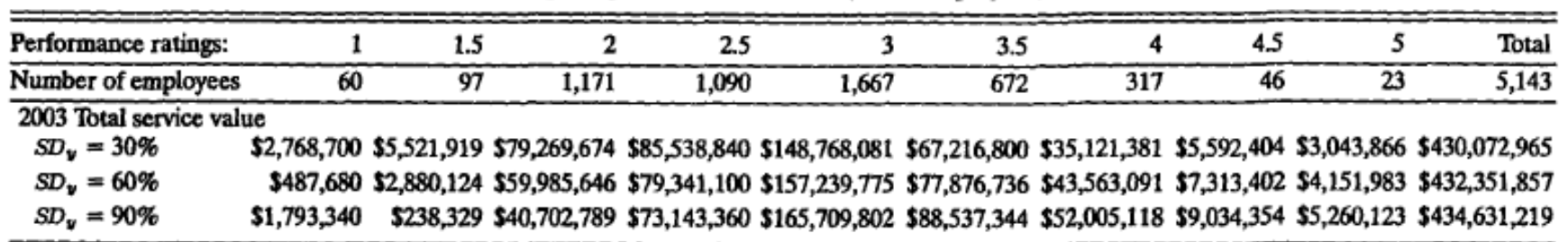

Note: The total service values are the same in 2003 regardless of pay strategy (although they do differ across $S D$, assumptions) because the three pay strategies had yet to result in the different performance-specific turnover patterns that begin in 2004 .

Finally, Table 8's service values of the replacements and Table 7's service values of retained employees were added to produce the estimated 2007 total service value for each pay strategy and $\mathrm{SD}_{\mathrm{y}}$ level combination, as shown in Table 9. We used these 2007 total service values, as well as the 2003 total service values from Table 6, to compute total service value across all years in Table 10. As we had done with total service costs computations, we calculated the 4-year stream of service value levels by assuming that service value rose linearly in each performance category between 2003 and 2007. Thus, for each pay strategy and $\mathrm{SD}_{\mathrm{y}}$ combination, we computed (a) the average service value increase (2007 service value minus 2003 service value, divided by four); (b) 2004 service value (2003 service value plus the average service value increase); (c) the average 2004-2007 service value (2004 service value plus 2007 service value, divided by 2); and (d), the total 2003-2007 service value (average 2003-2007 service value, times four, the number of years in our simulation).

TABLE 7

Total Service Value of Retained Employees (2007)

\begin{tabular}{|c|c|c|c|c|c|c|c|c|c|c|}
\hline Performance ratings: & 1 & 1.5 & 2 & 2.5 & 3 & 3.5 & 4 & 4.5 & 5 & Total \\
\hline & \multicolumn{10}{|c|}{ Retained emplorees } \\
\hline Pay Strategy 1 & 2 & 34 & 726 & 818 & 1,317 & 524 & 231 & 27 & 8 & 3,687 \\
\hline Pay Strategy 2 & 2 & 34 & 726 & 818 & 1,317 & 578 & 282 & 41 & 20 & 3,818 \\
\hline \multirow[t]{2}{*}{ Pay Strategy 3} & 1 & 12 & 468 & 709 & 1,317 & 578 & 282 & 41 & 20 & 3,428 \\
\hline & \multicolumn{10}{|c|}{ Total service value (2007) } \\
\hline \multicolumn{11}{|l|}{$S D_{v}=30 \%$} \\
\hline Pay Strategy 1 & $\$ 107,966$ & $\$ 2,264,264$ & $\$ 57,493,392$ & $\$ 75,096,490$ & $\mathbf{\$ 1 3 7 , 4 9 6 , 1 1 7}$ & $\$ 61,315,860$ & $\$ 29,940,141$ & $\$ 3,840,048$ & $\$ 1,238,560$ & $\mathbf{\$ 3 6 8 , 7 9 2 , 8 3 8}$ \\
\hline Pay Strategy 2 & $\$ 107,966$ & $\$ 2,264,264$ & $\$ 57,493,392$ & $\$ 75,096,490$ & $\$ 137,496,117$ & $\$ 67,634,670$ & $\$ 36,550,302$ & $\$ 5,831,184$ & $\$ 3,096,400$ & $\$ 385,570,785$ \\
\hline Pay Strategy 3 & $\$ 53,983$ & $\$ 799,152$ & $\$ 37, \mathbf{0 6 1}, 856$ & $\$ 65,089,745$ & $\$ 137,496,117$ & $\$ 67,634,670$ & $\$ 36,550,302$ & $\$ 5,831,184$ & $\$ 3,096,400$ & $\$ 353,613,409$ \\
\hline \multicolumn{11}{|c|}{ (4) } \\
\hline Pay Strategy 1 & $\$ 19,018$ & $\$ 1,180,990$ & $\$ 43,507,002$ & $\$ 69,655,154$ & $\$ 145,325,682$ & $\$ 71,039,728$ & $\$ 37,136,715$ & $\$ 5,021,757$ & $\$ 1,689,464$ & $\$ 374,575,510$ \\
\hline Pay Strategy 2 & $\$ 19,018$ & $\$ 1,180,990$ & $\$ 43,507,002$ & $\$ 69,655,154$ & $\$ 145,325,682$ & $\$ 78,360,616$ & $\$ 45,335,730$ & $\$ 7,625,631$ & $\$ 4,223,660$ & $\$ 395,233,483$ \\
\hline Pay Strategy 3 & $\$ 9,509$ & $\$ 416,820$ & $\$ 28,045,836$ & $\$ 60,373,477$ & $\$ 145,325,682$ & $\$ 78,360,616$ & $\$ 45,335,730$ & $\$ 7,625,631$ & $\$ 4,223,660$ & $\$ 369,716,961$ \\
\hline \multicolumn{11}{|c|}{ 由 } \\
\hline Pay Strategy 1 & $-\$ 69,932$ & $\$ 97,716$ & $\$ 29,520,612$ & $\$ 64,214,636$ & $\$ 153,153,930$ & $\$ 80,764,120$ & $\$ 44,333,058$ & $\$ 6,203,466$ & $\$ 2,140,368$ & $\$ 380,357,974$ \\
\hline Pay Strategy 2 & $-\$ 69,932$ & $\$ 97,716$ & $\$ 29,520,612$ & $\$ 64,214,636$ & $\$ 153,153,930$ & $\$ 89,087,140$ & $\$ 54,120,876$ & $\$ 9,420,078$ & $\$ 5,350,920$ & $\$ 404,895,976$ \\
\hline Pay Strategy 3 & $-\$ 34,966$ & $\mathbf{\$ 3 4 , 4 8 8}$ & $\$ 19,029,816$ & $\$ 55,657,918$ & $\$ 153,153,930$ & $\$ 89,087,140$ & $\$ 54,120,876$ & $\$ 9,420,078$ & $\$ 5,350,920$ & $\mathbf{\$ 3 8 5 , 8 2 0 , 2 0 0}$ \\
\hline
\end{tabular}


TABLE 8

Service Value of Replacement Employees (2007)

\begin{tabular}{lrrr}
\hline & \multicolumn{4}{c}{ Pay Strategy 1 Pay Strategy 2 Pay Strategy 3 } \\
\hline Average service value & $\$ 100,025$ & $\$ 100,025$ & $\$ 100,025$ \\
$S D_{y}=30 \%$ & $\$ 101,594$ & $\$ 101,594$ & $\$ 101,594$ \\
$S D_{y}=60 \%$ & $\$ 103,162$ & $\$ 103,162$ & $\$ 103,162$ \\
$S D_{y}=90 \%$ & 1,457 & 1,326 & 1,716 \\
Number of separations (2004-2007) & & & \\
Total service value of replacements (2007) & $\$ 145,736,425$ & $\$ 132,633,150$ & $\$ 171,642,900$ \\
$S D_{y}=30 \%$ & $\$ 148,022,458$ & $\$ 134,713,644$ & $\$ 174,335,304$ \\
$S D_{y}=60 \%$ & $\$ 150,307,034$ & $\$ 136,792,812$ & $\$ 177,025,992$ \\
$S D_{y}=90 \%$ & &
\end{tabular}

Note: We are using the conservative assumption that replacement employees will have the service value of employees under the first pay strategy. Our approach implicitly assumes that the pay strategy has no effect on recruitment or job performance of new employees. If we assumed that new employees had service values equal to the average service values of employees under the new pay strategies, then the total service value of replacements would be higher under Pay Strategies 2 and 3.

\section{TABLE 9}

Total Service Value of the 2007 Workforce

\begin{tabular}{|c|c|c|c|c|c|}
\hline & $\begin{array}{l}\text { Value of } \\
\text { retained } \\
\text { employees }\end{array}$ & + & $\begin{array}{l}\text { Value of } \\
\text { replaced } \\
\text { employees }\end{array}$ & $=$ & $\begin{array}{l}\text { Total value } \\
\text { (2007) }\end{array}$ \\
\hline \multicolumn{6}{|l|}{$S D_{y}=30 \%$} \\
\hline Pay Strategy 1 & $\$ 368,792,838$ & + & $\$ 145,736,425$ & $=$ & $\$ 514,529,263$ \\
\hline Pay Strategy 2 & $\$ 385,570,785$ & + & $\$ 132,633,150$ & $=$ & $\$ 518,203,935$ \\
\hline Pay Strategy 3 & $\$ 353,613,409$ & + & $\$ 171,642,900$ & $=$ & $\$ 525,256,309$ \\
\hline \multicolumn{6}{|l|}{$S D_{y}=60 \%$} \\
\hline Pay Strategy 1 & $\$ 374,575,510$ & + & $\$ 148,022,458$ & $=$ & $\$ 522,597,968$ \\
\hline Pay Strategy 2 & $\$ 395,233,483$ & + & $\$ 134,713,644$ & $=$ & $\$ 529,947,127$ \\
\hline Pay Strategy 3 & $\$ 369,716,961$ & + & $\$ 174,335,304$ & $=$ & $\$ 544,052,265$ \\
\hline \multicolumn{6}{|l|}{$S D_{y}=90 \%$} \\
\hline Pay Strategy 1 & $\$ 380,357,974$ & + & $\$ 150,307,034$ & $=$ & $\$ 530,665,008$ \\
\hline Pay Strategy 2 & $\$ 404,895,976$ & + & $\$ 136,792,812$ & $=$ & $\$ 541,688,788$ \\
\hline Pay Strategy 3 & $\$ 385,820,200$ & + & $\$ 177,025,992$ & $=$ & $\$ 562,846,192$ \\
\hline
\end{tabular}

Under all assumptions about $\mathrm{SD}_{\mathrm{y}}$ the 2007 and total service values are lowest when giving all employees average pay increases (Pay Strategy 1), are higher when giving high performers high pay increases and all others average increases (Pay Strategy 2), and are highest when the pay-forperformance link was strongest (Pay Strategy 3). Compared to Pay Strategy 1, which gives all employees average pay increases, Pay Strategy 2 prompts more high-performing and highly paid employees to stay, and their value enhances the work force. Pay Strategy 3 augments this effect by encouraging the turnover of low performers, who subsequently are replaced with workers whose expected value is that of average workers under Pay Strategy 1. 
TABLE 10

Computing 4-Year Total Service Value

\begin{tabular}{|c|c|c|c|}
\hline & Pay Strategy 1 & Pay Strategy 2 & Pay Strategy 3 \\
\hline \multicolumn{4}{|l|}{$S D_{y}=30 \%$} \\
\hline 2003 Service value & $\$ 430,072,965$ & $\$ 430,072,965$ & $\$ 430,072,965$ \\
\hline 2007 Service value & $\$ 514,529,263$ & $\$ 518,203,935$ & $\$ 525,256,309$ \\
\hline Average service value increase & $\$ 21,114,075$ & $\$ 22,032,743$ & $\$ 23,795,836$ \\
\hline 2004 Service value & $\$ 451,187,040$ & $\$ 452,105,708$ & $\$ 453,868,801$ \\
\hline Avg. (2004-2007 Service value) & $\$ 482,858,152$ & $\$ 485,154,822$ & $\$ 489,562,555$ \\
\hline Total service value (2004-2007) & $\$ 1,931,432,608$ & $\$ 1,940,619,288$ & $\$ 1,958,250,220$ \\
\hline \multicolumn{4}{|l|}{$S D_{v}=60 \%$} \\
\hline 2003 Service value & $\$ 432,351,857$ & $\$ 432,351,857$ & $\$ 432,351,857$ \\
\hline 2007 Service value & $\$ 522,597,968$ & $\$ 529,947,127$ & $\$ 544,052,265$ \\
\hline Average service value increase & $\$ 22,561,528$ & $\$ 24,398,818$ & $\$ 27,925,102$ \\
\hline 2004 Service value & $\$ 454,913,385$ & $\$ 456,750,675$ & $\$ 460,276,959$ \\
\hline Avg. (2004-2007 Service value) & $\$ 488,755,677$ & $\$ 493,348,901$ & $\$ 502,164,612$ \\
\hline Total service value (2004-2007) & $\$ 1,955,022,708$ & $\$ 1,973,395,604$ & $\$ 2,008,658,448$ \\
\hline \multicolumn{4}{|l|}{$S D_{y}=90 \%$} \\
\hline 2003 Service value & $\$ 434,631,219$ & $\$ 434,631,219$ & $\$ 434,631,219$ \\
\hline 2007 Service value & $\$ 530,665,008$ & $\$ 541,688,788$ & $\$ 562,846,192$ \\
\hline Average service value increase & $\$ 24,008,447$ & $\$ 26,764,392$ & $\$ 32,053,743$ \\
\hline 2004 Service value & $\$ 458,639,666$ & $\$ 461,395,611$ & $\$ 466,684,962$ \\
\hline Avg. (2004-2007 Service value) & $\$ 494,652,337$ & $\$ 501,542,200$ & $\$ 514,765,577$ \\
\hline Total service value (2004-2007) & $\$ 1,978,609,348$ & $\$ 2,006,168,800$ & $\$ 2,059,062,308$ \\
\hline
\end{tabular}

Hence, whereas our cost analysis suggested that Pay Strategy 3 was the least effective and Pay Strategy 1 was the most effective, our analysis of workforce value indicates the exact opposite.

Obviously, relying only on either cost or value estimates would be shortsighted. The critical question is whether the service value benefits of a strong pay-for-performance link outweigh the costs (Boudreau, 1991; Boudreau \& Ramstad, 2003a; 2003b).

Step 7: Determining the Final Utility-Is Pay-for-Performance worth It?

At this point, we return to the flow chart in Figure 1 and the question that motivated this research effort: Is it worth it to use pay-for-performance in an attempt to win the war for talent? To speak to this, we began by specifying three pay-plan strategies and estimating the subsequent turnover probabilities and performance distributions we would expect under each. Using this turnover and performance information, we then addressed costs for each pay plan through the estimation of expenses associated with employee movement out of and into the workforce and with the pay and benefits for the workforce. Having estimated costs, we turned to the benefits dimension of the costbenefit analysis and estimated the value of the retained workforce and of the replacement employees. Thus, we have estimated the three components for the decision of whether pay-for-performance makes sense in our example: (a) the 4-year stream of movement costs; (b) the 4-year stream of service costs; 
and (c), the 4-year stream of service value. Now, we combine these components to estimate the relative value of the three pay strategies by taking the stream of service value and subtracting the stream of service costs and movement costs (Boudreau \& Berger, 1985). The relevant amounts are summarized in Table 11 for each pay strategy and $\mathrm{SD}_{\mathrm{y}}$, assumption combination.

These results suggest a different conclusion from the cost analysis presented earlier. Recall that traditional compensation-cost analyses may have led decision makers to the conclusion that a strong link between pay and performance would be unwise given its extreme cost, and that although a moderate pay-for-performance link was not much more expensive than having no link, there were no cost-based data to strongly suggest it as a compelling alternative. When the potential benefits of workforce value are accounted for, however, it becomes clear that investments in performance-based pay may hold the potential for significant organizational improvement. Table 11 indicates that even under our most conservative $\mathrm{SD}_{\mathrm{y}}$ assumption, pay-for-performance plans yielded greater net values than did the noncontingent pay strategy. That is, by fully incorporating both costs and benefits into our assessment, we find that, under all of our conditions, pay-for-performance is indeed a valuable investment. Moreover, as $\mathrm{SD}_{y}$ (i.e., the value associated with performance differences) became larger, the payoff to pay-for-performance increased dramatically, ultimately (i.e., at So, $=90 \%$ ) resulting in advantages relative to the noncontingent pay from Pay Strategy 1 of over $\$ 26$ and $\$ 56$ million dollars for the partially contingent and highly contingent pay strategies, respectively.

TABLE 11

Computation of 4-Year Investment Value of Different Pay Strategies (in \$Millions)

\begin{tabular}{|c|c|c|c|c|c|c|c|c|c|}
\hline & $\begin{array}{l}\text { Service value } \\
\text { (in Smillions) }\end{array}$ & - & $\begin{array}{l}\text { Service costs } \\
\text { (in Smiltions) }\end{array}$ & - & $\begin{array}{l}\text { Movement costs } \\
\text { (in Smillions) }\end{array}$ & $=$ & $\begin{array}{l}\text { 4-Year value } \\
\text { (in Smillions) }\end{array}$ & $\begin{array}{c}\text { Difference from } \\
\text { Pay Strategy } 1\end{array}$ & $\begin{array}{l}\% \text { Change from } \\
\text { Pay Strategy } 1\end{array}$ \\
\hline \multicolumn{10}{|l|}{$S D_{y}=30 \%$} \\
\hline Pay Strategy 1 & $\$ 1,931.43$ & & $\$ 1,495.89$ & & $\$ 154.67$ & & $\$ 280.87$ & - & - \\
\hline Pay Strategy 2 & $\$ 1,940.62$ & & $\$ 1,509.66$ & & $\$ 142.05$ & & $\$ 288.91$ & $\$ 8.04$ & $2.86 \%$ \\
\hline Pay Strategy 3 & $\$ 1,958.25$ & & $\$ 1,492.95$ & & $\$ 181.80$ & & $\$ 283.50$ & $\$ 2.62$ & $0.91 \%$ \\
\hline \multicolumn{10}{|l|}{$S D_{y}=60 \%$} \\
\hline Pay Strategy 1 & $\$ 1,955.02$ & & $\$ 1,495.89$ & & $\$ 154.67$ & & $\$ 304.46$ & - & - \\
\hline Pay Strategy 2 & $\$ 1,973.40$ & & $\$ 1,509.66$ & & $\$ 142.05$ & & $\$ 321.69$ & $\$ 17.22$ & $5.66 \%$ \\
\hline Pay Strategy 3 & $\$ 2,008.66$ & & $\$ 1,492.95$ & & $\$ 181.80$ & & $\$ 333.91$ & $\$ 29.44$ & $9.15 \%$ \\
\hline \multicolumn{10}{|l|}{$S D_{v}=90 \%$} \\
\hline Pay Strategy 1 & $\$ 1,978.61$ & & $\$ 1,495.89$ & & $\$ 154.67$ & & $\$ 328.05$ & - & - \\
\hline Pay Strategy 2 & $\$ 2,006.17$ & & $\$ 1,509.66$ & & $\$ 142.05$ & & $\$ 354.46$ & $\$ 26.41$ & $8.05 \%$ \\
\hline Pay Strategy 3 & $\$ 2,059.06$ & & $\$ 1,492.95$ & & $\$ 181.80$ & & $\$ 384.31$ & $\$ 56.26$ & $15.87 \%$ \\
\hline
\end{tabular}

\section{Discussion}

This analysis suggests that even under conservative assumptions about the value of performance variability among employees, the 4-year financial benefit of linking pay to performance in 
this company would be substantial. When these $\mathrm{SD}_{\mathrm{y}}$ assumptions are closer to what we believe to be more realistic (i.e., if job performance differences have greater value to an organization), the present model reveals the potentially high payoff from investments in performance-based pay. Moreover, our analysis vividly illustrates the limitations of standard accounting and behavioral cost-based approaches for identifying the critical variables and, thus, the appropriate pay strategy.

\section{Simplifying Decisions}

Because utility analysis can be rather complex, we used a number of simplifying decisions here. First, we assumed that replacement employees would be of average performance level (and, thus, average service value). This implicitly assumes that pay-for-performance would not influence applicant attraction, even though research suggests that the degree to which pay and performance are linked does in fact matter to applicants (Cable \& Judge, 1994). Second, in focusing on the relationship between pay-for-performance and turnover, we made no provisions for whether the performance-based pay would actually improve workforce performance (net of retention effects). This implicit modeling of no effect of performance-based pay on performance is particularly noteworthy given that the contingent pay plan in the Trevor et al. (1997) study was sufficiently well designed to elicit a performance-specific retention pattern. Third, we were working with the relatively normally distributed performance distribution from the Trevor et al. sample. Although using this distribution simplified matters by allowing us to make use of other aspects of the Trevor et al. study, we recognize that many performance distributions may be characterized by a greater proportion of employees being rated in the top two or three performance categories and by the subsequent negative skew. The Trevor et al. distribution arose because the organization, consistent with its individualistic and hierarchical culture, encouraged differentiation among employees during performance appraisal. In addition, because 2evor et al. used averaged performance levels (with a mean of 3.05 performance ratings per employee), such factors as change in performance over time and random error in ratings combined to reduce the likelihood of having an average rating in the very top or bottom performance levels. To the extent that an organization with an aggressive pay-for-performance plan does encourage or mandate a normal performance distribution, however, the implications are noteworthy. For example, the system allocates large raises to the relatively few high performers, who should then be satisfied, motivated, and likely to remain; in contrast, the system also may frustrate, demotivate, and ultimately result in increased turnover among employees that might be reasonably high performers but were not rated as such as a result of the forced distribution. 
We emphasize that each of the three simplifying decisions was made to facilitate our presentation rather than strengthen our results. Indeed, each decision actually weakens the results' apparent support for performance-based pay. In unreported analyses, we incorporated into the utility analysis improved applicant quality under Pay Strategies 2 and 3, improved performance (net of retention effects) under Pay Strategies 2 and 3, and a more negative skew in the performance distribution. In each case, these alternative approaches to the decision in question resulted in a larger net advantage for Pay Strategy 2 and, to an even greater extent, for Pay Strategy 3. Thus, the analyses we presented here are a simplified and conservative approach. The spreadsheets available from the first author can be adapted to test such alternative assumptions.

\section{On Overcoming the "Futility of Utility"}

Our simplifying decisions notwithstanding, the analyses presented here entail much detail and speculation that, according to utility analysis criticism, might hinder their acceptance in managerial ranks. Indeed, we are quite aware of the "futility of utility" (Latham \& Whyte, 1994; Whyte \& Latham, 1997) findings in which utility analysis appeared to reduce managerial support for an HR intervention. To a large extent, the futility of utility problem likely resides within the presenter and recipients of utility analysis data, rather than with utility analysis itself. In defense of utility analysis, Sturman (2000) concludes that managers need to understand utility analysis and be trained in the use of the technology. Citing the necessity of managers making decisions based on the Merton and Scholes options pricing formula to have experience in finance and economics, Sturman (2000) argued that "For a complex decision making tool to be useful, the users of the decision aid must desire the information it provides and be trained in its use" (p. 297). Hence, rather than being apologists for the complexity of utility analysis, we believe that in-house I-O psychologists should attempt to convey that it is important for key stakeholders to have some basic grounding in sophisticated human resource decision making. Given that labor costs often comprise over half of all operating costs (Milkovich \& Newman, 2002), training decision makers in a decision tool designed to inform as to the optimal way to allocate these costs would appear to be a valid undertaking. On the presenter side, Cronshaw (1997), after participating as the expert utility presenter in the Whyte and Latham (1997) "futility" study, contended that "it is not utility analysis per se that imperils I-O psychologists, but the intemperate way it is often used. In effect, the messenger kills the message" (p. 614). Cronshaw advocated that utility analysis should be presented as an informational tool rather than as a "persuasive tool in a one-sided (and often self-serving) attempt to 'sell' innovations to managers" (p. 614). 
Boudreau and Ramstad $(1999 ; 2002)$ noted that the powerful influence of disciplines such as finance and marketing evolved from their focus on enhancing decisions about the key resource (money or customers), rather than on selling accounting or sales programs, and suggested that the influence of HR and I-O professionals will increase with a similar focus on talent decisions. They suggested (Boudreau \& Ramstad, 2002, 2003a; 2003b) the HC BRidge ${ }^{\circledR}$ decision model for "talent" resources that draws upon well developed decision models to delineate three fundamental elements: efficiency, effectiveness, and impact. The present analysis vividly shows the value of integrating "efficiency" (payroll and movement costs); "effectiveness" (changes in movement patterns); and "impact" (value of improvements in performance) into a decision support model, and the dangers of decision frameworks based solely on efficiency or effectiveness alone.

In addition to these emphases on decision-maker training and on presenting utility analysis as an informative tool rather than marketing it as a panacea, we also offer a few additional suggestions that might assist the I-O psychologist in communicating utility analyses. First, expectations should be set at the outset by affirming that the evaluation will be somewhat complex, just as would be expected from manufacturing, finance, or accounting. Any simplistic attempt to estimate performance-based pay's effects on the bottom line would be superficial and incomplete. Second, communicating the utility analysis would probably benefit from an initially broad explanation. Perhaps using something similar to our Figure 1 as a guide, the practitioner should emphasize the simple cost-benefit concepts of movement costs, service costs, performance-specific retention, and the critical, but often overlooked, workforce value. We believe that it would be wise to continually hearken back to these big picture concepts, with emphasis on effects rather than on measures (Cascio, 2000) and technical details (Hoffman, 1996). Third, acceptance may be facilitated via emphasis on the conservative nature of the assumptions, decisions, and subsequent estimates (Hoffman, 1996). Finally, highlighting the rationale for these assumptions and decisions should demystify them, and using the spreadsheets to instantaneously show the effects of changing them may provide valuable "best case" and "worse case" scenarios. Together, these recommendations should assist in indicating that well designed performancebased pay is worth considering and that HR is able to quantitatively evaluate the relevant alternatives.

\section{Limitations and Conclusions}

Several limitations are noteworthy. Our results reflect one organization's characteristics, such as plan specifics, the individual job performance distribution, and the relationship between pay-forperformance and turnover. The extent to which this organization, its employees, and our conclusions 
are representative of other firms and employees with regard to these factors is unknown. What is critical, however, is that the approach we took to finding these results can be applied in a wide variety of situations, thus enabling the examination of external validity. A second limiting factor in our study is that there may be additional pay strategy-specific training costs or administrative costs that we did not include. We believe, however, that such costs could easily be incorporated into this framework. Third, as discussed throughout this study, we made a number of assumptions and decisions in order to conduct the analyses. Although we believe that we took the most logical and conservative approaches at these junctures, viable arguments could be made for approaches different from our own. Fourth, although we modeled employees' performance levels as stable over time, research has shown that employee performance levels change over time (e.g., Deadrick, Bennett, \& Russell, 1997; Ployhart \& Hakel, 1998; Sturman \& Trevor, 2001). Furthermore, changes in performance levels are related to the likelihood of turnover, even after controlling for the effects of current performance levels (Harrison et al., 1996; Sturman \& Trevor, 2001). Considering the movement of employees between different performance categories across years, and the implications of these movements for forecasting turnover, would certainly add complexity to the model we presented. It may be valuable for future research to explore the implications of these model refinements.

The method we describe involves a significant amount of calculation, but is relatively simple to replicate on a spreadsheet. Actual replication may require some customization to fit a specific company's profile, but the basic premise of the methods should be the same. We hope that this demonstration will inspire organizations to more fully tap available research findings to help them enhance their HR policy decision making. We also hope that this paper helps demonstrate the value of research findings like those reported in Trevor et al. (1997) and will be complemented by future research on additional factors that may influence the pay-for-performance link with turnover. For example, satisfaction with different types of pay-for-performance plans (e.g., raises vs. bonuses) can have different effects on outcomes of organizational interest, such as job satisfaction and organizational commitment (Sturman \& Short, 2000). Ideally, the research presented here will encourage extensions of this work that can prove valuable for both understanding HR practices in general and for evaluating specific HR policies.

Organizations of all types will likely respond to increasing pressures to "win the talent war" by employing all available tools to enhance attraction, selection, and retention processes. A formidable tool in this endeavor is the accumulated knowledge available from I-O psychology and HR research. The method described here illustrates how utility analysis can be used to demystify and integrate this 
research, making it a more practical decision-making tool, and, thus, a more potent influence on significant strategic organizational goals (Boudreau, 1991; Boudreau \& Ramstad, 1997; 1999; 2002; 2003a; 2003b).

\section{References}

Bartlett CA, Ghoshal S. (2002). Building competitive advantage through people. MIT Sloan Management Review, 43(2), 34-41.

Becker BE, Huselid MA. (1992). Direct estimates of $S D_{y}$ and the implications for utility analysis. Journal of Applied Psychology, 77,227-233.

Berman JM. (2001). Industry output and employment projections to 2010. Monthly Labor Review, 124(11), 39-56.

Boudreau JW. (1991). Utility analysis for decisions in human resource management. In Dunnette MD, Hough LM (Eds.), Handbook of industrial and organizational psychology, 2nd ed., (Vol. 2, pp. 621-745). Palo Alto, CA Consulting Psychology Press.

Boudreau JW, Berger CJ. (1985). Decision-theoretic utility analysis applied to employee separations and acquisitions [Monograph]. Journal of Applied Psychology, 70, 581-612.

Boudreau JW, Ramstad PM. (2002). From "professional business partner" to "strategic talent leader": 'What's next for human resource management. Working Paper 02-10, Center for Advanced Human Resource Studies, Cornell University, Ithaca, NY.

Boudreau JW, Ramstad PM. (2003a). Strategic HRM measurement in the 21st century: From justifying HR to strategic talent leadership. In Goldsmith M, Gandossy RP, Efron MS (Eds.), HRM in the 2Ist Century, (pp. 79-90). New York Wiley

Boudreau JW, Ramstad PM. (2003b). Strategic I-O psychology and the role of utility analysis models. In Borman W, Ilgen D, Klimoski R (Eds.), Handbook of pychology, (Vol. 12, pp. 193-221). New York Wiley.

Boudreau JW, Ramstad PM. (1999). Human resource metrics: Can measures be strategic? In Wright P, Dyer L, Boudreau J, Milkovich G (Eds.), Strategic human resources management in the twentyfirst century. [Supplement 4 to G.R. Ferris (Ed.), Research in personnel and human resource management (pp. 75-98)]. Stamford, CT: JAI Press.

Boudreau JW, Ramstad PM. (1997). "Measuring intellectual capital: Learning from financial history." Human Resource Management, 36(3), 343-356.

Branch S. (1998, November 9). You hired 'em, but can you keep 'em? Fortune, 138, 247-250. 
Bureau of Labor Statistics. (2002). National compensation survey: Occupational wages in the United States, 2001. [On-line data source]. Washington, DC US Department of Labor, Bureau of Labor Statistics. Retrieved from http://wwr.bls.gov/ncdocs/sp/ncbl.449.pdf

Cable DM, Judge TA. (1994). Pay preference and job search decisions: A person-organization fit perspective. Personnel Psychology, 47,317 - 348.

Cascio WF. (2 000). Costing human resources: The financial impact of behavior in organizations (4th ed.). Boston: Kent.

Chambers EG, Handfield-Jones H, Hanking SM, Michaels EG III. (1998, December). Win the war for top talent. Workforce, 50-56.

Cronshaw SE (1997). Lo! The stimulus peaks: The insiders view on Whyte and Latham's "the futility of utility analysis." Personnel Psychology, 50, 611-616.

Deadrick DL, Bennett N, Russell CJ. (1997). Using hierarchical linear modeling to examine dynamic performance criteria Over time. Journal of Management, 23, 745-757.

Dreher GE (1982). The role of performance in the turnover process. Academy of Management Journal, 25, 137-147.

Fullerton HN Jr, Toosi M. (2001). Labor force projections to 2010: Steady growth and changing composition. Monthly Labor Review, 124(11), 21-38.

Gerhart B. (2000). Compensation strategy and organizational performance. In Rynes SL, Gerhart B (Eds.), Compensation in organizations. San Francisco: Jossey-Bass.

Gerhart B, Milkovich W. (1992). Employee compensation: Research and practice. In Dunnette MD, Hough L (Eds.), Handbook of industrial and organizational psychology, 2nd ed., (Vol. 3, pp. 481569). Palo Alto, CA Consulting Psychologists Press.

Griffeth RW, Hom PW, Gaertner S. (2000). A meta-analysis of antecedents and correlated of employee turnover: Update, moderator tests, and research implications for the next millennium. Journal of Management, 26, 463-488.

Harrison DA, Virick M, William S. (1996). Working without a net: Time, performance, and turnover under maximally contingent rewards. Journal of Applied Psychology, 81, 331-345.

Hewitt Associates. (2002). Twenty-sixth annual U.S. salary increase survey. Lincolnshire, IL Author. Hoffman CC. (1996). Applying utility analysis to guide decisions on selection system content. Journal of Human Resource Costing and Accounting 1, 9-17.

Hollenbeck JR, Williams CR. (1986). M o v e r functionality versus turnover frequency: A note on work attitudes and organizational effectiveness. Journal of Applied Psychology, 71, 606-611. 
IOMA. (2002, May). Pay for performance report. New York Institute of Management and Administration. Jackofsky EF. (1984). Turnover and job performance: An integrated process model. Academy of Management Review, 9, 74-83.

Jenkins DG Jr, Mitra A, Gupta N, Shaw JD. (1998). Are financial incentives related to performance? A meta-analytic review of empirical research. Journal of Applied Psychology, 83, 777-787.

Johnson A.A. (1995). The business case for work-family programs. Journal of Accountancy, 180(2), 53-57. Judiesch MK, Schmidt FL, Mount MK. (1992). Estimates of the dollar value of employee output in utility analyses: An empirical test of two theories. Journal of Applied Psychology, 77, 234-250.

Kalbfleisch JD, Prentice RL. (1980). The statistical analysis of failure time data. New York Wiley.

Klass BS, McClendon JA. (1996). To lead, lag, or match: Estimating the financial impact of pay level policies. Personnel Psychology, 49, 121-141.

Kohn A. (1993, September-October). Why incentive plans cannot work. Harvard Business Review, 54-63. Latham GP, Whyte G. (1994). The futility of utility analysis. Personnel Psychology, 47, 31-46.

McKinsey Br Company. (1998). The war for talent. New York McKinsey \& Company.

Milkovich GT, Newman JM. (2002). Compensation (7th ed). Boston, MA: Irwin.

Morita JG, Lee Tw, Mowday m. (1993). The regression-analog to survival analysis: A selected application to turnover research. Academy of Management Journal, 36, 1430-1464.

Peck C. (2002, June). Salary increase budgets: 2002 increases fall in many industries, rebound projected for 2003. Executive Action, 24, 1-5.

Pfeffer J. (1998, May/June). Six dangerous myths about pay. Harvard Business Review, 76, 108-120.

Ployhart RE, Hake1 MD. (1998). The substantive nature of performance variability: Predicting interindividual differences in intraindividual performance. Personnel Psychology, 51, 859-901.

Porter LW, Lawler EE. (1968). Attitudes and performance. Homewood, Hi Irwin-Dorsey.

Raju NS. Burke MJ, Normand J. (1990). A new approach for utility analysis. Journal of Applied Psychology, 75, 3-12.

Retherford RD, Choe MK. (1993). Statistical models for causal analysis. New York: Wiley.

Rich JT (1999, March/April). The growth imperative. The Journal of Business Strategy, 20, 27-31.

Schmidt FL, Hunter JE. (1983). Individual differences in productivity: An empirical test of estimates derived from studies of selection procedure utility. Journal of Applied Psychology, 68, 407-414.

Schmidt FL, Hunter JE, Outerbridge AN, Trattner MH. (1986). The economic impact of job selection methods on size, productivity, and payroll costs of the federal work force: An empirically based demonstration. Personnel Psychology, 39, 1-29. 
Schwab DP. (1991). Contextual variables in employee performance-mover relationships. Academy of Management Journal, 34, 966-975.

Sherwyn DS, Sturman MC. (2002). Job-sharing in the hotel industry: A potential new human resource tool resulting from the events of September 11th. Cornell Hotel and Restaurant Administration, 43(5), 84-91.

Solomon J. (1988, December 29). Companies try measuring cost savings from new types of corporate benefits. The Wall Street Journal, B1.

Steers RM, Mowday RT (1981). Employee turnover and the post decision accommodation process. In Staw BM, Cummings LL (Eds.), Research in organizational behavior (pp. 235-281). Greenwich, CT JAI Press.

Sturman MC. (2000). Implications of utility analysis adjustments for estimates of human resource intervention value. Journal of Management, 26, 281-299.

Sturman MC, Short JC. (2000). Lump-sum bonus satisfaction: '\&sting the construct validity of a new pay satisfaction dimension. Personnel Psychology, 53, 673-700.

Sturman MC, Trevor CO. (2001). The implications of linking the dynamic performance and employee turnover literatures. Journal of Applied Psychology, 86, 684-696.

Trevor CO. (2001). Interactive effects among actual ease of movement determinants and job satisfaction in the prediction of voluntary mover. Academy of Management Journal, 44, 621-638.

Trevor CO. Gerhart B, Boudreau JW. (1997). Voluntary turnover and job performance: Curvilinearity and the moderating influences of salary growth and promotions. Journal of Applied Psychology, 82, 44-61.

U.S. Department of Labor. (2001, March). Employer Costs for Employee Compensation. Washington, DC U.S. Department of Labor.

Whyte G, Latham GP. (1997). The futility of utility analysis revisited When even an expert fails. Personnel Psychology, 50, 601-610.

Williams CR, Livingstone LP. (1994). Another look at the relationship between performance and voluntary turnover. Academy of Management Journal, 37, 269-298.

WorldatWork. (2002). 29th Annual Report on the 2002-2003 Total Salary Increase Budget

Survey. Scottsdale, AZ: WorldatWork. 


\section{Appendix}

Computing Separation Probabilities Using Survival Analysis Results

Our estimation uses the survival analysis from Trevor et al.'s (1997) Table 4 (model 1).

Probability of survival $=S(0)^{e(S x)}$

where $S(0)$ = baseline probability of survival, which was 0.77 ,

$\beta=$ a vector of survival analysis regression coefficients,

$\chi=$ a vector of independent variables,

$(\beta \chi)=4.941+0.314 \times$ Salary Growth $-2.541 \times$ Performance $+0.553 \times$ Performance $^{2}-0.020 x$

Performance $^{3}+0.007 \times$ Salary Growth ${ }^{3}-0.663 x$ Salary Growth $x$ Performance $+0.071 \times$ Salary Growth $x$ Performance

The salary growth data used to estimate the equation above was measured in thousands of dollars. Thus, to use the equation, our example's percentage increases had to be converted to a parallel salary growth measure for each pay strategy and performance level combination. ?b do so, we determined the average pay growth under each strategy by subtracting 2003 pay from 2007 pay, dividing by 4 , and then dividing this amount by 1,000 .

For example, under Pay Strategy 3 and Performance Level 2.5, the average pay increase was $([\$ 54,005-\$ 47,983] / 4) / 1,000=1.5055$. The table below lists the salary growth for each pay strategy and performance level.

\begin{tabular}{lccccccccc}
\hline \hline $\begin{array}{l}\text { Performance } \\
\text { category }\end{array}$ & 1.0 & 1.5 & 2.0 & 2.5 & 3.0 & 3.5 & 4.0 & 4.5 & 5.0 \\
\hline Strategy 1 & 2.0375 & 2.0375 & 2.0375 & 2.0375 & 2.0375 & 2.0375 & 2.0375 & 2.0375 & 2.0375 \\
Strategy 2 & 2.0375 & 2.0375 & 2.0375 & 2.0375 & 2.0375 & 2.5853 & 3.1485 & 3.7283 & 4.3243 \\
Strategy 3 & 0.000 & 0.4870 & 0.9888 & 1.5055 & 2.0375 & 2.5853 & 3.1485 & 3.7283 & 4.3243 \\
\hline
\end{tabular}

Next, we need to estimate separation probability (i.e., 1 - probability of survival):

$1-S(0)^{\mathrm{e}(\beta \chi)}$

For example, for performers rated at 5.0 under Pay Strategy 2, the pay increase of $8 \%$ translates to an average dollar increase (in thou- sands) of 4.3243 , which yields a separation probability = $1--77$ 
$\mathrm{e}(\beta x)=1-.77^{\mathrm{e}(4.941-5.467)}=1-.77^{(0.5910)}=1-.086=.14$. Table 2 for separation probabilities at each performance level/pay strategy combination.

The 4.941 constant in the $(\beta \chi)$ calculation resulted from adding the estimated model constant (6.810) from Trevor et al.3 (1997) equation to the sum of the model terms that included neither performance nor salary growth (e.g., age, promotions). These terms were evaluated at the means of the respective $x$ variables. As an aside, we advocate centering variables prior to conducting hazard analyses, which causes the model constant and variables set at their means to drop out, thus simplifying the calculation of survival probabilities (Retherford \& Choe, 1993; Trevor, 2001). See Trevor (2001) and Morita et al. (1993) for more on computing survival probabilities. 